\title{
Accounting for global-mean warming and scaling uncertainties in climate change impact studies: application to a regulated lake system
}

\author{
B. Hingray, N. Mouhous, A. Mezghani, K. Bogner, B. Schaefli and A. Musy \\ Laboratory of Hydrology and Land Improvement, Ecole Polytechnique Fédérale de Lausanne, Switzerland \\ Email for corresponding author: benoit.hingray@gmail.com
}

\begin{abstract}
A probabilistic assessment of climate change and related impacts should consider a large range of potential future climate scenarios. State-ofthe-art climate models, especially coupled atmosphere-ocean general circulation models and Regional Climate Models (RCMs) cannot, however, be used to simulate such a large number of scenarios. This paper presents a methodology for obtaining future climate scenarios through a simple scaling methodology. The projections of several key meteorological variables obtained from a few regional climate model runs are scaled, based on different global-mean warming projections drawn in a probability distribution of future global-mean warming. The resulting climate change scenarios are used to drive a hydrological and a water management model to analyse the potential climate change impacts on a water resources system. This methodology enables a joint quantification of the climate change impact uncertainty induced by the global-mean warming scenarios and the regional climate response. It is applied to a case study in Switzerland, a water resources system formed by three interconnected lakes located in the Jura Mountains. The system behaviour is simulated for a control period (1961-1990) and a future period (2070-2099). The potential climate change impacts are assessed through a set of impact indices related to different fields of interest (hydrology, agriculture and ecology). The results obtained show that future climate conditions will have a significant influence on the performance of the system and that the uncertainty induced by the inter-RCM variability will contribute to much of the uncertainty of the prediction of the total impact. This research has been conducted within the 2001-2004 EU funded project SWURVE.
\end{abstract}

Keywords: climate change impact, regional response pattern scaling, Monte Carlo simulation, hydrological modelling, uncertainty analysis, impact analysis, Switzerland.

\section{Introduction}

The assessment of climate change impacts on water resources is currently subject to intense research (see, e.g. Jasper et al., 2004; Kim, 2005; Lettenmaier et al., 1999; Loukas et al., 2002). The quantification of these impacts is conditional on the availability of regional climate change predictions of different key meteorological variables such as precipitation and surface air temperature. Currently available regional climate changes projections are generally based on the results of coupled Atmosphere-Ocean General Circulation Models (AOGCMs) or on the results of Regional Climate Models (RCMs) that are driven by the outputs of the former and that are supposed to describe regional climatic variables better than AOGCMs because of their higher spatial resolution $\left(0.5^{\circ}\right.$ latitude $\times 0.5^{\circ}$ longitude or higher).
Regional climate change projections based on climate model outputs are highly uncertain, mainly due to the unknown future greenhouse gas emissions but also due to the highly simplified representation of reality encoded in these models. As a consequence, different state-of-the-art AOGCMs generally simulate different climate evolutions for the same emission scenario (see, e.g. Arnell and Hulme, 2000; Räisänen, 2001, 2002). For a given AOGCM experiment, the corresponding RCM experiment is also subject to these modelling uncertainties. The results of several RCM experiments based on the same AOGCM outputs can therefore also differ significantly (see, e.g. Frei et al., 2003; Raïsänen et al., 2004). Nevertheless, the uncertainty introduced by the RCM is generally considered to be substantially smaller than the one inherited by the driving AOGCM (Jenkins and Lowe, 2003). As part of the 
2001-2004 EU project SWURVE (Sustainable Water, Uncertainty, Risk and Vulnerability in Europe, see Kilsby et al., 2007), an analysis of the data of the EU project PRUDENCE (Prediction of Regional scenarios and Uncertainties for Defining EuropeaN Climate change risks and Effects (Christensen et al., 2002) suggests, however, that the inter-RCM variability cannot be neglected (Ekström et al., 2007; Hingray et al., 2007).

An evaluation of the full range of potential climate change impacts on a given water resources system would require taking into account the uncertainties due to different emission scenarios and due to the climate model structure and the corresponding parameterization (for both AOGCMs and RCMs). This would need a large number of AOGCMRCM experiments with different emission scenarios. However, climate model simulations being highly timeconsuming, only a few model experiments are currently available. Consequently, most impact studies are reduced to a scenario analysis: meteorological variables are obtained for a limited number of climate models and of probable greenhouse gas emission scenarios. Such approaches can neither simulate all possible system outcomes nor assign them a probability of occurrence.

Recent work addresses the assignment of such probabilities of occurrence through Monte Carlo simulation frameworks (New and Hulme, 2000; Jones, 2000; Prudhomme et al., 2003), combining some of the major sources of uncertainty such as the emission scenarios, the global climate sensitivity and the inter-climate model variability. However, most of the studies currently available take no account of all sources of modelling uncertainty. Prudhomme et al. (2003), for example, include different Global Circulation Model (GCM) patterns and climate sensitivities but their analysis is based on only four emission scenarios defined by the Intergovernmental Panel on Climate Change (IPCC) in its Special Report on Emission Scenarios (SRES) (Nakienovi and Swart, 2000).

The scaling approach introduced by Santer et al. (1990) enables the generation of multiple climate change scenarios for a number of global-mean warming projections. The technique is currently widely used in climate scenario studies (New and Hulme, 2000; Jones, 2000; Hulme et al., 2002) and is based on the assumption of a linear relationship between the annual global-mean warming (the so-called scaler) and the response pattern of regional climate changes obtained from any global or regional climate model. In the work of Jones (2000) and of New and Hulme (2000), the response pattern is expressed for each variable as a simple scaling ratio, i.e. a constant regional temperature or precipitation change per degree of global-mean warming. The response pattern used by Mitchell (2003) is the spatial climate change pattern of a GCM. The advantage of this scaling technique is that the scaler can be obtained from socalled Simple Climate Models (SCMs) demanding fewer computing resources than GCMs (Wigley et al., 2000). Based on such SCMs, thousands of Monte Carlo simulations can be produced (New and Hulme, 2000; Huntingford and Cox, 2000). Wigley and Raper (2001) present such an approach to determine the Probability Distribution Function (PDF) of global-mean warming between 1990 and different periods in the $21^{\text {st }}$ century. A simple upwelling-diffusion energy balance model is calibrated against the results of seven state-of-the-art AOGCMs. The emission uncertainties as well as the uncertainties due to the climate sensitivity, the carbon cycle, the ocean vertical diffusivity and the aerosol forcing are characterised by appropriate PDFs, which are then used to drive the SCM resulting in PDFs of the global-mean warming. SCMs are, however, not sufficiently complex to represent with accuracy spatial or seasonal patterns of climate changes, especially if regional features are needed for small space and time resolutions. This problem can be overcome by a technique of pattern scaling that combines SCM and RCM (or GCM) outputs to produce a number of climate change scenarios (Mitchell, 2003).

The methodology presented in this paper is based on such a scaling approach. It was developed during the 2001-2004 EU project SWURVE. Future climate scenarios - in terms of seasonal changes of the mean value and of the variability of temperature and precipitation - are obtained for the period 2070-2099 by scaling the meteorological response pattern from a RCM by a global-mean warming projection randomly drawn from a PDF obtained from Wigley and Raper (2001). The uncertainty inherent in the regional climate response is taken into account through the use of different meteorological response patterns derived from a set of RCM experiments available through the PRUDENCE project (Christensen et al., 2002).

The corresponding local scale time series of surface air temperature and precipitation are obtained through a classical perturbation procedure (Shabalova et al., 2003). These series are used as an input to simulate the behaviour of a water resources system for future climate change conditions. The performance of the resulting system is compared with a control period based on an appropriate set of performance indices. This methodology is applied to a managed lake system located in the north-west of Switzerland. The control period analysed is 1961-1990 and the future period 2070-2099. These 30-year periods are assumed to cover a large part of the natural variability of the system and to be long enough for a climate change impact to be assessed. 
In this paper, after introducing the models developed to simulate the behaviour of the system and indices of the impact of climate change, the climatic datasets and the climate scenarios are presented, followed by a discussion of the probabilistic framework for stochastic climate scenario generation. Finally, the main results and the relative importance of the different sources of uncertainty in climate modelling are discussed.

\section{Case study: a regulated lake system}

\section{SYSTEM DESCRIPTION}

The water resources system studied in the north-west of Switzerland (Fig. 1) comprises three interconnected lakes, formed 15000 years ago during the retreat of the Rhone glacier. The system was modified significantly in the periods 1833-1884 and 1963-1972 by the construction of connection channels (Jaton, 1989). Different regulation waterworks have been built to reduce the flood risk and to transform the formerly unproductive areas into fertile arable land. The interconnection of the three lakes equilibrates their water levels and the mean daily level of all of them is roughly the same. The catchment surface area of the three lakes is around $8300 \mathrm{~km}^{2}$ (Fig. 1) and its elevation ranges from $420 \mathrm{~m}$ a.s.l. (at the outlet of lake Bienne) to around $4270 \mathrm{~m}$ a.s.l. with a mean elevation of $1150 \mathrm{~m}$ a.s.l. The three main inflows into the lakes are the rivers Aare, Broye and Orbe (Fig. 1, and see Table 1 for catchment characteristics).

\section{HYDROLOGICAL REGIME}

The hydrological regimes of the Aare and Broye rivers located in the Swiss Alps and Prealps are influenced significantly by snowmelt; less than $3 \%$ of the Aare catchment is covered by glaciers. The Orbe River and several other tributaries to Lakes Bienne and Neuchatel are in the Swiss Jura Mountains; consequently, their hydrological regimes are influenced by snowmelt and karst effects. The hydrological regime of all these rivers has a marked seasonality, with low flows in winter and high flows from spring to autumn due to snowmelt and rainfall. Artificial lakes (mainly used for hydropower production) and regulated natural lakes perturb the river regimes, especially that of the Aare River (Spreafico et al., 1992).

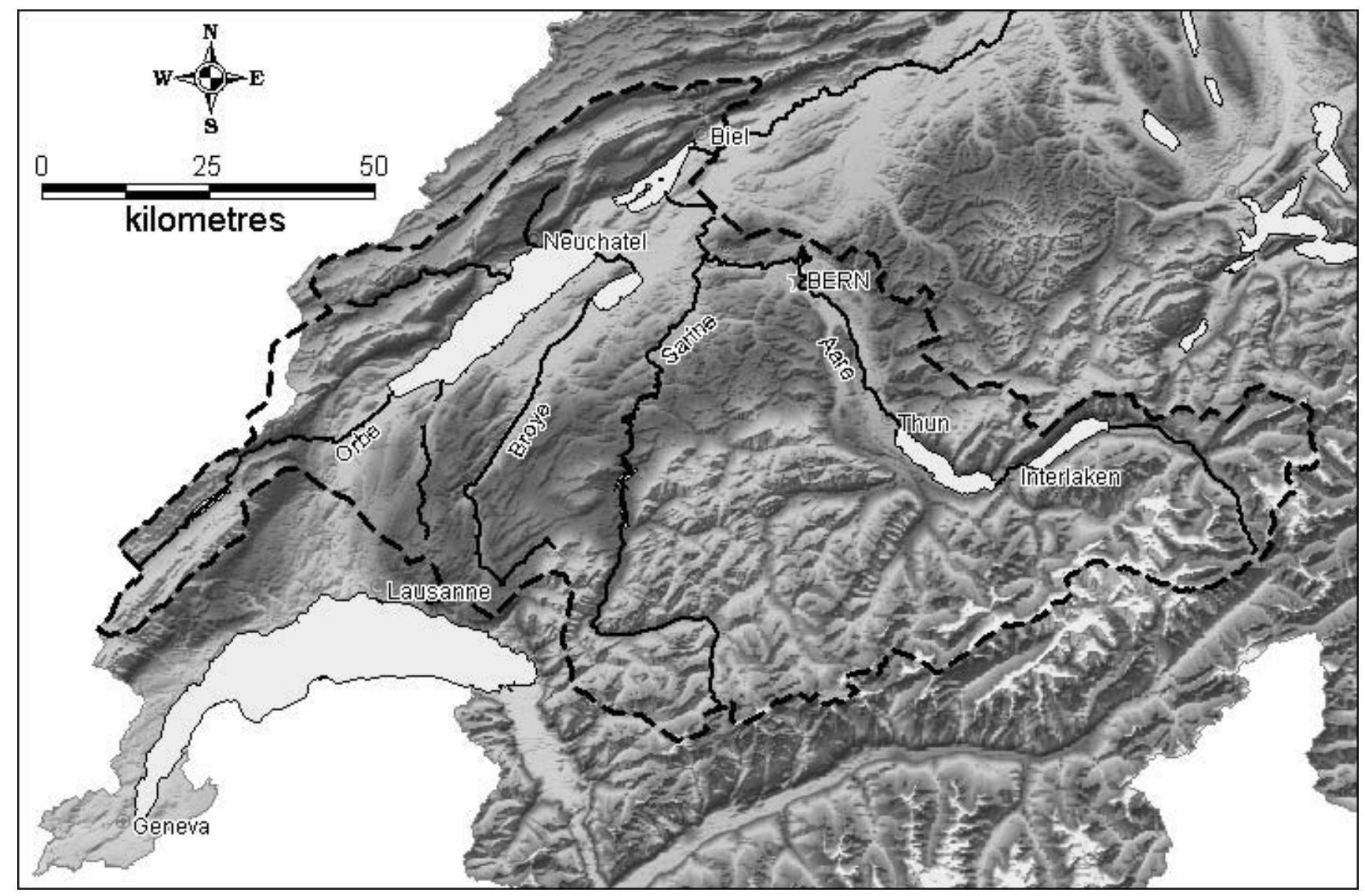

Fig. 1. Location of the lake system studied in the Swiss Alps (SwissTopo, 1997) 
Table 1. Characteristics of the main rivers feeding the studied lakes system

\begin{tabular}{llll}
\hline & Aare River & Broye River & Orbe River \\
\hline Catchment area & $5128 \mathrm{~km}^{2}$ & $392 \mathrm{~km}^{2}$ & $333 \mathrm{~km}^{2}$ \\
Gauge & Hageneck & Payerne & Orbe \\
Outlet & Lake of Bienne & Lake of Morat & Lake of Neuchâtel \\
Elevation range & $450-4250 \mathrm{~m}$ a.s.l. & $450-2000 \mathrm{~m}$ a.s.l. & $450-1500 \mathrm{~m}$ a.s.l. \\
$\begin{array}{l}\text { Hydrological regime } \\
\text { influenced by }\end{array}$ & Snowmelt & Snowmelt & Karsts \\
& Lake regulation & & Snowmelt \\
& Hydropower & & Hydropower \\
\hline
\end{tabular}

\section{LAKE REGULATION}

The only discharge of the lake system, at Nidau-Port (Lake Bienne), is regulated by a weir and water is released according to 'règlement $80 / 82$ ' approved by the Swiss Federal Government (VAW, 1996). Daily target releases are fixed as a function of the water level in the lakes and of the calendar day. These rules have been elaborated to take account of the sometimes conflicting interests of the different stakeholders involved in farming, fishery, hydropower production, flood protection and ecosystem conservation (including wetland protection). The resulting water level is low in winter and high in summer. The maximum annual water level fluctuation is, however, less than $1 \mathrm{~m}$.

\section{POTENTIAL FAILURES AND CLIMATE CHANGE IMPACTS}

For most stakeholders, potential system failures are related directly to the water level of the lakes. The main failures occur when the lake level is above a critical level because of an unexpected or long-lasting high water inflow. Such situations can lead to water-logging and flooding of agricultural areas (particularly damaging during the sowing season) and riparian urban areas (Jaton, 1989). Other failure events are induced by persistent droughts. Such situations can lead to economic losses for agriculture (water restriction and irrigation targets unachievable) or for the hydropower plants located downstream of the lake. In addition, the welfare of many animal and vegetal species depends on the temporal progression of the water level throughout the year. Pikes, for example, need a sudden spring flood to access their spawning area and their alevins need a slow flood decrease to return to the deeper water (Zaugg et al., 1994). Highly specialised birds build their nests in the reeds just above the maximum water level experienced during the days preceding the brooding. A significant water level increase after nest construction floods some of them (Aebischer, 1994).

A potential climate change is expected to modify the hydrological regime of the different rivers feeding the lakes. The resulting modified temporal evolution of the lake levels potentially influences the frequency, duration and intensity of failures occurring.

\section{System modelling}

\section{DATA COLLECTION}

An integrated simulation tool, developed to simulate the performance of the system under different climates, includes hydrological models to simulate river discharges feeding the lakes with a management model for the simulation of the lake level evolution. The development and calibration of these models is based on observations. The observed precipitation and surface air temperature time series for the hydrological models are obtained from the Swiss Meteorological Institute at a daily time step. Potential evapotranspiration is estimated based on the PennmanMonteith model (Monteith and Unsworth, 1990) and direct evaporation from the lake surface is estimated by the Turc formula (Mermoud, 1995). Observations of river discharge and lake level are obtained from the Swiss Federal Office of Water and Geology. Based on these data, the hydrological and management models were calibrated for the years 19841992 and validated for the years 1993-2000.

\section{HYDROLOGICAL MODELLING}

The catchment feeding the lake system is split into its three main sub-catchments named Aare, Broye and Jura (the last includes several small rivers as well as the River Orbe). For each of these sub-catchments, a specific hydrological model has been developed. The present modelling context - 
namely the simulation of a high number of scenarios and the limited available meteorological data for future scenarios — imposed the development of highly parsimonious discharge models.

All catchments are strongly influenced by snow accumulation and snowmelt processes. In the present simulation framework, these processes are taken into account by computing a rainfall equivalent to the sum of rainfall and simulated snowmelt. For a catchment glaciercovered in parts, this equivalent rainfall should include ice melt but the computation of the equivalent rainfall for the Aare catchment accounts only for snowmelt. This is because, for the control period, the area of the catchment on which ice melt processes occur is insignificant: only $3 \%$ of the catchment area is glacierised and the corresponding mean ablation area (the area where ice melt occurs) can be assumed to cover only around one-third of the total glacier area (see, e.g. Maisch et al., 2000).

Hereafter, the snowmelt computation is presented, followed by a short description of the equivalent rainfalldischarge transformation that is specific to each of the three catchments. The daily snow accumulation and snowmelt depend strongly on the mean daily precipitation and temperature, both of which are spatially very variable and altitude-dependent. Given the large elevation ranges of the catchments studied, they were divided into several elevation bands to simulate the snow pack evolution.

For each elevation band, the daily precipitation is divided into rain- and snowfall according to a fuzzy-threshold established by Steel (1999) for the whole of Europe. The daily snowmelt is computed according to the modified degree-day method of Schreider et al. (1997). Instead of the constant degree-day factor as in the classical degreeday formulation (Martinec et al., 1983), an albedo-related factor was calculated for each month of the year as a function of the mean monthly temperature. This function was established empirically by Whetton et al. (1996) and has been adapted to European conditions by Steel (1999).

The equivalent rainfall is transformed into discharge through an appropriate runoff model for each subcatchment. As the Broye catchment has a rather natural hydrological behaviour, a classical conceptual modelling approach is applied (a lumped rainfall-runoff model), combining a nonlinear loss module based on the moisture deficit in the catchment with the routing module of the rainfall-runoff model IHACRES (Jakeman and Hornberger, 1993). The accounting scheme for the non-linear loss module converts equivalent rainfall into rainfall excess, while the routing module relates rainfall excess to total streamflow via two parallel linear reservoirs.

The Aare catchment is highly influenced by water derivations, i.e. where water is collected from subcatchments and routed via artificial collectors to other subcatchments, and by several regulated natural and artificial lakes. The hydrological regime of the Jura catchment is influenced significantly by karsts. As it is unrealistic to simulate the discharge of these two catchments by simple conceptual models, the Data-Based Mechanistic (DBM) modelling approach proposed by Young and Beven (1994) has been tested. In this approach, the most parsimonious model structure is inferred statistically from the available time series, using the time variable parameter estimation method called Fixed Interval Smoothing (FIS) presented by Young (1984) and Young (1993).

For the Aare and Jura catchments, the DBM modelling approach highlighted the predominating effect of the lagged runoff, resulting in an autoregressive model where the rainfall as driving forces is negligible. Such an approach is, clearly, not applicable in climate change impact studies. The elimination of the autoregressive part of the DBM model led to a linear regression model between the daily discharge and the equivalent rainfall filtered by moving averages. The same filtering is applied to the temperature series in the regression model as a second explanatory variable. For the Aare catchment, the final model has seven parameters, the constants $a_{1}, b_{1}, b_{2}, b_{3}$, and the window sizes $w_{i}$ for the moving average filtering:

$$
Q_{t}=a_{1}+b_{1} \cdot \frac{1}{w_{1}} \sum_{k=1}^{w_{1}} P_{t-k}^{\text {Aare }}+b_{2} \cdot \frac{1}{w_{2}} \sum_{k=1}^{w_{2}} T_{t-k}+b_{3} \cdot \frac{1}{w_{3}} \sum_{k=1}^{w_{3}} P_{t-k}^{\text {Sarine }}
$$

where $Q_{t}$ is the simulated discharge on day $t$ and $T_{t-k}$ is the mean temperature for the entire Aare catchment for day $t-k$. $P_{t-k}^{\text {Aare }}$ and $P_{t-k}^{\text {Sarine }}$ are the area average equivalent rainfall for the two subcatchments upper-Aare and Sarine. A similar multiple regression model has been developed for the Jura catchment.

Using the coefficient of determination $\left(R^{2}\right)$ as an objectivefunction, the values of $R^{2}$ for the calibration period are, respectively, $0.77,0.68$ and 0.89 for the Aare, Jura and Broye catchments; for the validation period the values are 0.67 , 0.43 and 0.97 . Bearing in mind the parsimony constraints and the highly disturbed hydrological regimes, the performance of the three models is rather good.

\section{MANAGEMENT MODEL}

The simulation of the temporal evolution of the water levels is based on a simple water balance model accounting for lake inflow, direct evaporation from the lake surfaces and water release at the unique system outlet. The water routing through the hydraulic system and especially between the 
lakes is assumed to be negligible. The water release is simulated according to the regulation rules (VAW, 1996) that determine the release as functions of the observed lake level (estimated through appropriate storage-to-level functions) and of the calendar day. Except for a few extreme situations, the weir manager follows these regulation rules strictly and, consequently, the observed water levels are well simulated (Denk, 2002).

\section{SYSTEM PERFORMANCE MEASUREMENT}

Because of the high number of stakeholders directly concerned about the temporal evolution of the lake level, an integrated assessment of all potential impacts of climate change is impossible. Hence, attention has been directed at three particular fields of interest, namely, agriculture (focusing on spring crops), fishery (focusing on pikes), flood protection (focusing on flooding of riparian urban areas) and wetland protection (focusing on the reed population in the Grande Cariçaie ecosystem).

To judge the behaviour of water resources systems under different future climatic situations, a pertinent set of criteria has to be defined. These should be discriminant and easily calculable and they should not be redundant, i.e. there should be no or little correlation between the information encoded in respect of the different criteria. Because the main interest is concerned with the ability of the system to deal with future uncertain climate conditions without severe damage, the robustness of the system i.e. its capacity to absorb adverse conditions without lasting damage, must be one of the criteria. The system may fail but should be able to recover rapidly. Hashimoto et al. (1982) have defined the RRV criteria (Reliability, Resilience and Vulnerability); they measure how often a system failure occurs, how severe it is and how quickly the system returns to a satisfactory state afterwards. These criteria can be interpreted as probabilistic measures of the frequency, duration and intensity of occurring failures. They are quantitative risk criteria and, therefore, highly adapted to climate change impact analysis. Several applications appear in the literature (Lane et al., 1999; Vogel et al., 1999; Fowler et al., 2003).

The use of RRV criteria for the lake system studied requires definition of the acceptability of outputs of the system under examination. This task may be straightforward - as for a drinking water supply system for example - or quite difficult - as for agriculture or flood protection in the present case study. For agriculture, high water levels during the sowing season will delay access to the land or may inundate the seeds by water logging after sowing. During the maturation season, flooding over several consecutive days could affect the harvest and reduce the productivity significantly. For a given field, at a given altitude compared to the lake level, a critical lake water level can be identified. The different fields are however not at the same altitude compared to the lake level.

Similarly, the water level threshold for urban flood damage varies (430.35 m a.s.1., $430.70 \mathrm{~m}$ a.s.1., $430.25 \mathrm{~m}$ a.s.l. for the lakes of Neuchâtel, Morat and Bienne ). The extent of damage can be modelled as a function of the number of buildings and infrastructure affected by the inundation. This depends on the intensity of the flood and on the altitude of the riparian urban zones. As was found for agriculture, a unique critical water threshold is difficult to define.

The analysis of impacts on animal or vegetal species is even more complex. The definition of a proper failure state is difficult mainly because the interaction between the physical system and the studied populations is difficult to measure and can evolve with time. In the present study, potential climate change impacts are quantified through socalled welfare indices. Two different types have been defined: one measures the success of reproduction of pikes and the other the viability of reed. For the pikes, the relationship between the reproduction success and the annual lake level evolution is known (Zaugg et al., 1994). For reed, the long-term viability can be expressed as a function of the maximum fluctuation of the water level (Buttler et al., 1995; Clerc, 1999). All welfare indices have been evaluated on a yearly time step. Based on these annual time series, an intensity- frequency-duration analysis of the occurring events is completed. Such an analysis is comparable to an RRV-analysis even if the events analysed events are not necessarily failures.

The same approach has been adopted for analysing potential climate change impacts on all identified fields of interest. In the following, the events analysed have been summarised:

- Reed population: annual maximum water level fluctuation defined as the difference between the annual minimum daily water level and maximum daily water level.

- Pike population: the annual reproduction success score is $\mathrm{SO}$, the product of four different scores $\mathrm{S} 1$ to $\mathrm{S} 4$, each of which has a value between 0 and 1 and is related to a different aspects of success in reproduction. To reach their spawning areas, pikes need a sudden spring flood, the magnitude of which gives score S1 and the minimum expected variation in level is $30 \mathrm{~cm}$. Score S2 is determined by the arrival date of this spring flood and the best date is $15^{\text {th }}$ February. The final water level, which determines the extent of accessible spawning areas, should reach at least $429.9 \mathrm{~m}$ a.s.l. and gives score 
S3. Score S4 measures the speed of flood decrease. Pike alevins need a slow decrease in flood to return to deep water, ideally less than $10 \mathrm{~cm}$ per 100 days and this rate gives Score S4. If conditions are optimal in a given year, all the scores are set to 1; otherwise, they are decreased according to Zaugg et al. (1994).

- Flood protection of urban areas: annual maximum flood is defined as the annual maximum daily water level.

- Spring crop: seasonal failure events are defined for the sowing season (spring) and the maturation season (summer) if the minimum daily water level over $n$ consecutive days ( $n=2$ for sowing season, $n=10$ for maturation season) is above a given threshold $H \mathrm{~s}_{\mathrm{i}}$ that is expected to produce water logging in the sowing period in spring and field inundation in summer when the crops mature.

\section{Pattern scaling and time series generation}

\section{GENERATION OF FUTURE TIME SERIES FOR A GIVEN CLIMATE CHANGE SCENARIO}

Based on a probability distribution of the future global-mean warming and on available AOGCM and RCM model outputs, the generated future time series must meet the following requirements. (i) They should reflect the seasonality of regional climate changes. For the catchments studied, the mean temperature increase is expected to be higher in summer than in winter (Hingray et al., 2007). (ii) For the meteorological variables (surface air temperature and precipitation), they should reflect changes both in the mean and in variability. Potential climate related impacts are generally highly dependent on extreme events. As the occurrence of extreme events is highly sensitive to the width of statistical distributions, changes in variability are generally supposed to influence their occurrence more than changes in averages (Katz and Brown, 1992; Mearns et al., 1996; Schär et al., 2004). Nevertheless, changes in variability are rarely taken into account in the development of future time series scenarios. As they can be estimated easily from outputs of climate model experiments, they should be integrated in a time series generation framework.

The method of Shabalova et al. (2003) is well adapted for the development of such time series scenarios for daily mean precipitation and temperature. Local scale meteorological time series for a given future scenario (here 2070-2099) are generated by perturbing the observed series for a control period (here 1961-1990). The perturbation preserves the changes in mean and variability given by the climate change scenario. This scenario is defined by the following seasonal statistics: The absolute change of the mean temperature $(X M T)$ and the relative change of the mean precipitation $(X M P)$, of the standard deviation of daily temperature $(X S D T)$ and of the coefficient of variation of daily precipitation $(X C V P)$. The perturbation equation for temperature is,

$$
T_{s c e n, s}(t)=\left[T_{o b s, s}(t)-M T_{o b s, s}\right]^{*}\left(X S D T_{s}+1\right)+M T_{o b s, s}+X M T_{s}
$$

where $T_{\text {scen,s }}(t)\left({ }^{\circ} \mathrm{C}\right)$ is the local scale scenario temperature on day $t$ of season $s$ ( $s=1$ : DJF; $s=2$ : MAM; $s=3$ : JJA; $s=4$ : SON). $T_{o b s, s}(t)\left({ }^{\circ} \mathrm{C}\right)$ is the observed temperature on day $t$ of season $s$ and $M T_{o b s, s}\left({ }^{\circ} \mathrm{C}\right)$ is the observed mean temperature of season $s . X M T_{s}$ is the absolute change in the mean temperature of season $s$ (defined as the mean temperature of the RCM output for the future period minus the mean temperature of the RCM output for the control period) and $X S D T$ is the relative change of the standard deviation of the daily temperature of season $s$ (defined as the difference between the values obtained from the RCM output for the future period and the control period divided by the value for the control period).

The perturbation of the daily rainfall series is described in Appendix 1. A perturbation method similar to that for temperature is not used because this would generate negative rainfall values. Shabalova et al. (2003) fit a Weibull distribution to the observed daily rainfall amounts and the Weibull parameters of the perturbed series are computed based on the parameters of the observed distribution according to the relative changes in precipitation mean and variability predicted by the climate scenario.

\section{GENERATION OF CLIMATE CHANGES SCENARIOS}

The objective of the generation of multiple climate change scenarios is twofold: (i) to enable the generation of regional climate change scenarios for a large range of possible globalmean warming predictions and (ii) to account for the uncertain regional response to a given global-mean warming scenario (i.e. for the uncertainty related to the inter-RCM variability). Additionally, the scenario generation methodology has to preserve the correlations between the seasonal changes in temperature and precipitation predicted by the RCM experiments.

The prediction uncertainty due to the global-mean warming has been highlighted in previous studies and has been characterised, for example, by Wigley and Raper (2001). The uncertainty due to inter-model variability has been described for the mean values of different key meteorological variables and for their variability (e.g. 
Räisänen, 2001; Räisänen, 2002). The temporal correlation between some of the key variables might well be significant. New and Hulme (2000) have highlighted a significant positive correlation between winter precipitation and temperature changes for Scotland and East Anglia. For the case study presented in this paper, the correlation between the four mean seasonal temperature changes is not negligible, partly because these changes are strongly related to the global-mean warming. Another explanation arises from the high correlations between the seasonal scaling ratios obtained from some climate experiments, such as the correlation between seasonal DJF and MAM temperatures shown in Fig. 3). To take these correlations into account, the pattern scaling technique discussed earlier has been adopted.

\section{PATTERN SCALING}

The generation of temperature and precipitation time series according to the above perturbation methodology requires regional climate change statistics as input. These statistics correspond to a 16-values matrix $\boldsymbol{X}=\left[X M T_{s}, X S D T_{s}, X M P_{s}\right.$, $\left.X C V P_{s}\right]_{s: 1 . .4}$. In the following, a different notation for $\boldsymbol{X}$ is

$$
\boldsymbol{X}=\left[\boldsymbol{X}_{v, s}\right]_{v: 1 . .4, s: 1 . .4}
$$

where $X_{v, s}$ is one key statistic $v$ of the daily mean temperature or precipitation series $\left(X_{1, s}=X M T_{s}, X_{2, s}=X S D T_{s}, X_{3, s}=X M P_{s}\right.$, $X_{4, s}=X C V P_{s}$ ) and where $s$ refers to the season.

Given a RCM called $r$ that has been run for the control period (1961-1990) and the future period (2070-2099), the response pattern is defined as the following matrix

$$
\boldsymbol{Y}_{r}=\left[Y_{V, s, r}\right]_{V: 1 . .4, s: 1.4}
$$

where $Y_{v, s, r}$ is the scaling ratio for one of the four key statistics $\operatorname{used}\left(Y_{1, s, r}=Y M T_{s, r}, Y_{2, s, r}=Y S D T_{s, r}, Y_{3, s, r}=Y M P_{s, r}, Y_{4, s, r}=\right.$ $\left.Y C V P_{s, r}\right)$ for season $s$ and RCM experiment $r$. For each variable, the scaling ratio is defined as its regional change (absolute or relative) per degree of global-mean warming. For a given RCM experiment $r$, the scaling ratios are estimated based on

$$
Y_{v, s, r}=X_{v, s, r} / \Delta T_{r}
$$

where $X_{v, s, r}$ is the change in variable $v$ for season $s$ predicted by RCM experiment $r$ between the control and the future period and $\Delta T_{r}$ is the global-mean warming value obtained for the AOGCM used to drive RCM experiment $r$.

Based on the outputs of a RCM experiment, a range of regional climate change scenarios can be generated by scaling their response patterns according to different globalmean warming predictions drawn in an appropriate globalmean warming PDF. If several RCM experiments are available, a range of scenarios can be generated for each of the corresponding response patterns and, accordingly, the uncertainty of the regional climate response to a given global-mean warming scenario can be quantified.

The pattern scaling technique is based on the critical assumption that there is a linear relationship between the scaler (annual global-mean warming) and the response pattern of regional climate changes obtained from the climate model. For a given climate model (in the present case for an AOGCM/RCM configuration), the validity of this assumption can be analysed if several climate experiments are available for different radiative forcing scenarios. Mitchell et al. (1999) and Mitchell (2003) have examined this assumption for spatial changes in mean temperature and precipitation from ten climate change experiments obtained with the HadCM2 GCM. Their results indicate that for the model studied, pattern scaling could be applicable to a wide range of variables. For the present work, not more than two climate change experiments are available for each AOGCM/ RCM configuration. The reliability of the assumption of linearity is, thus, difficult to check. Figure 2 presents regional changes in temperature and precipitation versus global-mean warming for six AOGCM/RCM configurations having climate experiments for both $\mathrm{A} 2$ and $\mathrm{B} 2$ emission scenarios. From these experiments, the linearity assumption seems to hold well for changes in mean seasonal temperatures and precipitation but the relationship is weaker for changes in temperature and precipitation variability. In the absence of any further climate experiments, it was decided to retain the assumption of linearity for all the variables studied. Note that it would be difficult to assess the reliability of this linear scaling assumption from all climate experiments available in this work. Non-negligible deviations from a mean linear scaling relationship are actually expected (e.g. Fig. 2 in Hingray et al., 2007). Such deviations do not, however, necessarily contradict the assumed linear scaling relationship between regional changes and global-mean warming. They could be also due to differences between the models or to the effects of the natural variability in the climate model response.

DATASET: REGIONAL RESPONSE PATTERNS OF 26 RCMS

The present study has used a set of 26 RCMs experiments, each comprising simulations for the control 1961-1990 and for the future period 2070-2099, carried out in the framework of the EU project PRUDENCE (Christensen et 

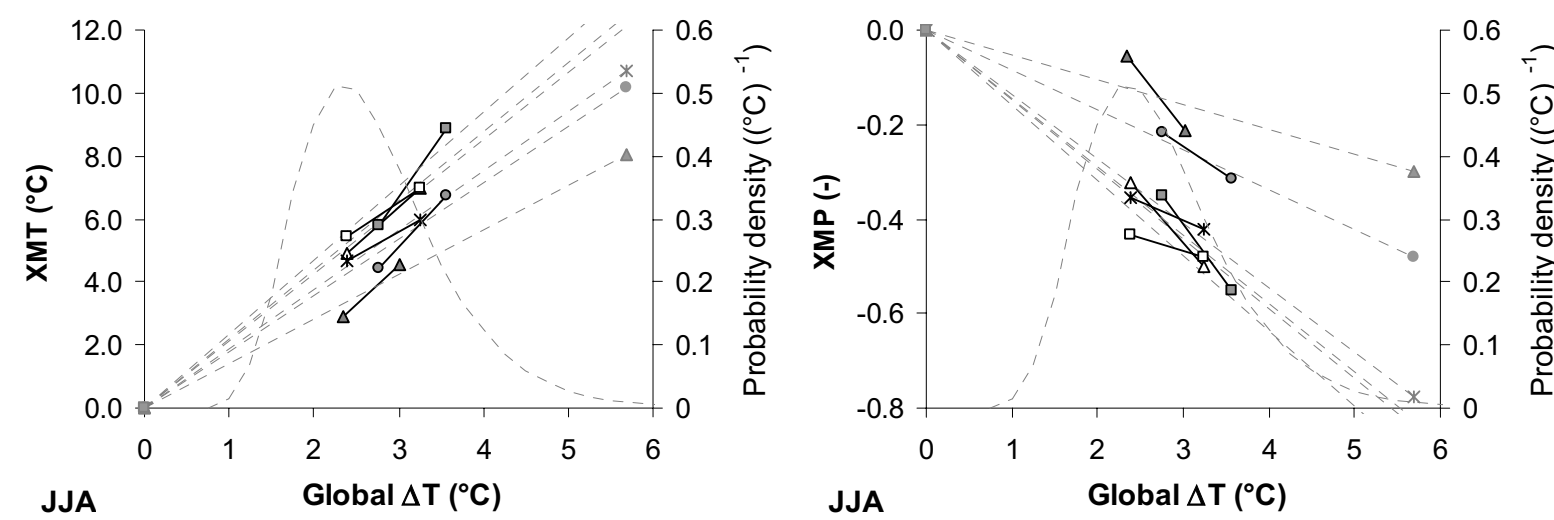

1
0
0
3
$\frac{7}{0}$
$\frac{0}{0}$
0
0
$\frac{1}{2}$
$\frac{0}{\pi}$
0
0
0
0
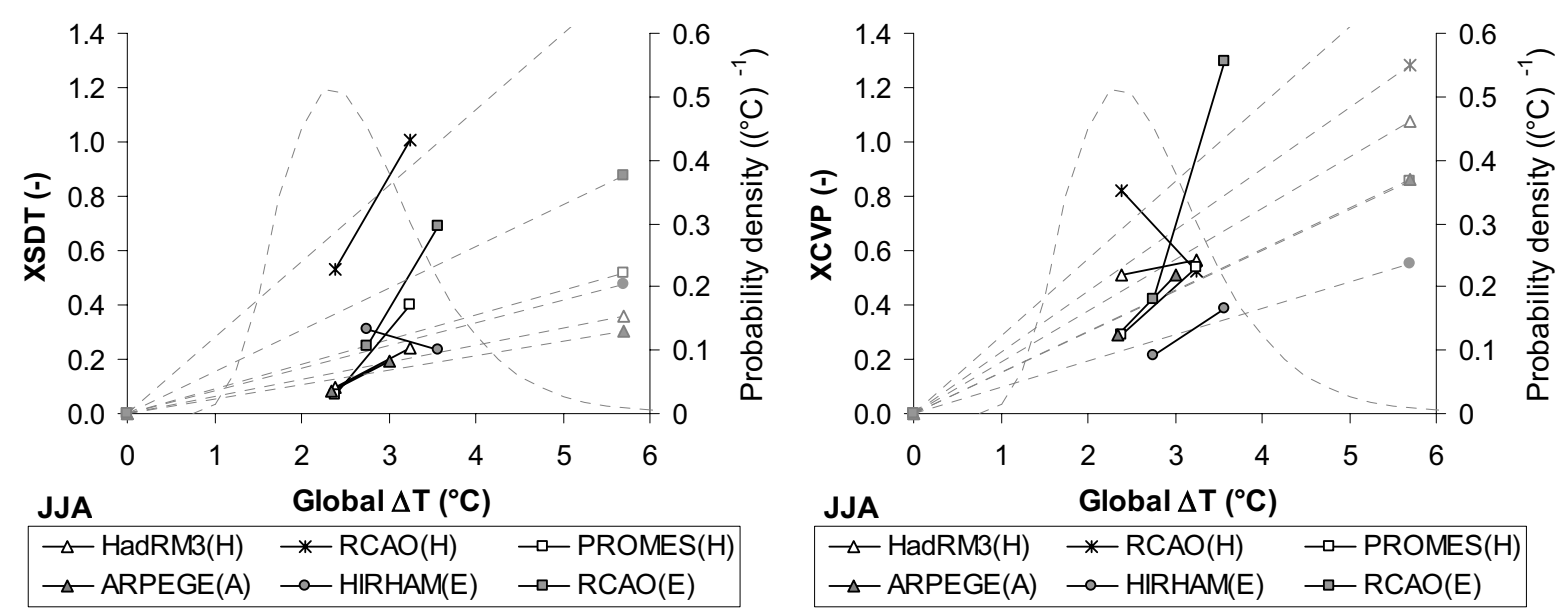

Fig. 2. Scaling relationships between regional climate changes and global-mean warming $(\Delta \mathrm{T})$ for the summer season. Left: regional changes in seasonal temperature (top: changes in mean, XMT; bottom: changes in variability, XSDT). Right: regional changes in seasonal precipitation (top: changes in mean, XMP; bottom: changes in variability, XCVP). Each symbol corresponds to one AOGCM/RCM configuration for which experiments are available for both A2 and B2 emission scenarios. If ensemble runs are available, only one run is plotted. For each configuration, the straight line is based on a least-squares fit to the two climate experiments. Linear regressions are forced to pass through the origin. Note that $\Delta \mathrm{T}$ is not specific to the summer season. The grey dashed curve is the probability density function of globalmean warming from 1990 to the period 2070-2099 obtained from Wigley and Raper (2001).

al., 2002). The boundary conditions for these simulations have been obtained from the three AOGCMs used in the PRUDENCE project: ARPEGE/OPA (Royer et al., 2002), HadCM3 (Gordon et al., 2000; Pope et al., 2000) and ECHAM4/OPYC3 (Roeckner et al., 1999). In the case of HadCM3, use of a global model of the atmosphere alone (HadAM3H) between the global coupled model and the RCMs resulted in a much improved simulation of the present-day climate (Hulme et al., 2002). All AOGCMs have been run for the SRES A2 and SRES B2 emission scenarios (Nakicenovic and Swart, 2000). The corresponding values of global-mean warming are given in Table 2 .

For the present study, nine different RCMs were available (see Table 3 for a list of the models and the corresponding modelling institutions). However, one of these models,
ARPEGE, is not a regional but a global atmospheric model with variable horizontal resolution, from $50 \mathrm{~km}$ in the centre of the Mediterranean to $450 \mathrm{~km}$ in the southern Pacific Ocean (Gibelin and Déqué, 2003). In PRUDENCE, the low boundary conditions (sea surface temperatures, sea ice) have been obtained from ARPEGE/OPA and HadCM3 (Déqué, 2004 , pers. comm.). For the lake system studied, the horizontal resolution of ARPEGE is comparable with that of the other RCMs and so ARPEGE is treated as an RCM in this paper.

Some RCMs have been run successively using the boundary conditions of different AOGCMs. All RCMs have been run at least for scenario A2 with one AOGCM. Some RCMs have also been run for scenario B2. In total, 19 different AOGCM/RCM experiments are available, 12 of 
Table 2. Clusters of the RCM experiments of the PRUDENCE project according to the driving AOGCM and to the emission scenario $(\Delta T=$ globalmean warming, $*=2$ ensemble runs are available, $* *=3$ ensemble runs are available)

\begin{tabular}{|c|c|c|c|c|c|}
\hline & $\mathrm{AOC}$ & $\mathrm{CM}$ & $\mathrm{RCM}$ & & \\
\hline Scenario & No. & Name & $\Delta T$ & No. & Name \\
\hline \multirow[t]{12}{*}{ A2 } & \multirow[t]{9}{*}{1} & HADCM3/HADAM3H & 3.25 & 1 & $\mathrm{CHRM}(\mathrm{H})$ \\
\hline & & HADCM3/HADAM3H & 3.25 & 2 & $\operatorname{CLM}(\mathrm{H})$ \\
\hline & & HADCM3/HADAM3H & 3.25 & $3 * *$ & $\operatorname{HadRM} 3 \mathrm{H}(\mathrm{H})$ \\
\hline & & HADCM3/HADAM3H & 3.25 & $4^{*}$ & $\operatorname{HIRHAM}(\mathrm{H})$ \\
\hline & & HADCM3/HADAM3H & 3.25 & 5 & PROMES(H) \\
\hline & & HADCM3/HADAM3H & 3.25 & 6 & $\mathrm{RCAO}(\mathrm{H})$ \\
\hline & & HADCM3/HADAM3H & 3.25 & 7 & $\operatorname{RegCM}(\mathrm{H})$ \\
\hline & & HADCM3/HADAM3H & 3.25 & 8 & $\operatorname{REMO}(\mathrm{H})$ \\
\hline & & HADCM3/ARPEGE & 3.25 & $9 * *$ & ARPEGE(H) \\
\hline & 2 & ARPEGE/ OPA & 3.02 & 10 & ARPEGE(A) \\
\hline & \multirow[t]{2}{*}{3} & ECHAM4/OPYC3 & 3.56 & 11 & HIRHAM(E) \\
\hline & & ECHAM4/OPYC3 & 3.56 & 12 & $\mathrm{RCAO}(\mathrm{E})$ \\
\hline \multirow[t]{7}{*}{ B2 } & \multirow[t]{4}{*}{4} & HADCM3/HADAM3H & 2.39 & 13 & $\operatorname{HadRM} 3 \mathrm{H}(\mathrm{H})$ \\
\hline & & HADCM3/HADAM3H & 2.39 & 14 & PROMES(H) \\
\hline & & HADCM3/HADAM3H & 2.39 & 15 & $\mathrm{RCAO}(\mathrm{H})$ \\
\hline & & HADCM3/ARPEGE & 2.39 & 16 & ARPEGE(H) \\
\hline & 5 & ARPEGE/ OPA & 2.35 & $17 * *$ & ARPEGE(A) \\
\hline & \multirow[t]{2}{*}{6} & ECHAM4/OPYC3 & 2.76 & 18 & HIRHAM(E) \\
\hline & & ECHAM4/OPYC3 & 2.76 & 19 & $\mathrm{RCAO}(\mathrm{E})$ \\
\hline
\end{tabular}

Table 3. (a) the three AOGCM and (b) the nine RCM models used in the PRUDENCE project (Christensen et al., 2002) and the corresponding modelling institutions

\begin{tabular}{|c|c|c|c|}
\hline Acronym & Institution & $A O G C M$ & Reference \\
\hline \multicolumn{4}{|l|}{ (a) } \\
\hline CNRM & $\begin{array}{l}\text { Centre National de Recherches Météorologiques, } \\
\text { Toulouse, France }\end{array}$ & ARPEGE/OPA & Royer et al., 2002 \\
\hline $\mathrm{HC}$ & $\begin{array}{l}\text { Hadley Centre for Climate Prediction and Research, } \\
\text { Bracknell, United Kingdom }\end{array}$ & HadCM3 & $\begin{array}{l}\text { Gordon et al., } 2000 \\
\text { Pope et al., } 2000\end{array}$ \\
\hline MPI & Max-Planck-Institut für Meteorologie, Hamburg, Germany & ECHAM4/OPYC3 & Roeckner et al., 1999 \\
\hline \multicolumn{4}{|l|}{ (b) } \\
\hline CNRM & $\begin{array}{l}\text { Centre National de Recherches Météorologiques, } \\
\text { Toulouse, France }\end{array}$ & ARPEGE & Gibelin and Déqué, 2003 \\
\hline DMI & Danish Meteorological Institute, Copenhagen, Denmark & HIRHAM & Christensen et al., 2001 \\
\hline ETHZ & $\begin{array}{l}\text { Institute for Atmospheric and Climate Science, } \\
\text { Zurich, Switzerland }\end{array}$ & CHRM & Vidale et al., 2003 \\
\hline GKSS & Institute for Coastal Research, Geesthacht, Germany & CLM & Doms and Schättler, 1999 \\
\hline $\mathrm{HC}$ & $\begin{array}{l}\text { Hadley Centre for Climate Prediction and Research, } \\
\text { United Kingdom }\end{array}$ & HadRM3H & Hulme et al., 2002 \\
\hline ICTP & International Centre for Theoretical Physics, Trieste, Italy & RegCM & Giorgi et al., 1993ab \\
\hline MPI & Max-Planck-Institut für Meteorologie, Hamburg, Germany & REMO & Jacob, 2001 \\
\hline SMHI & $\begin{array}{l}\text { Swedish Meteorological and Hydrological Institute, } \\
\text { Norrköping, Sweden }\end{array}$ & $\mathrm{RCAO}$ & Räisänen et al., 2004 \\
\hline UCM & Universidad Complutense de Madrid, Toledo, Spain & PROMES & Arribas et al., 2003 \\
\hline
\end{tabular}



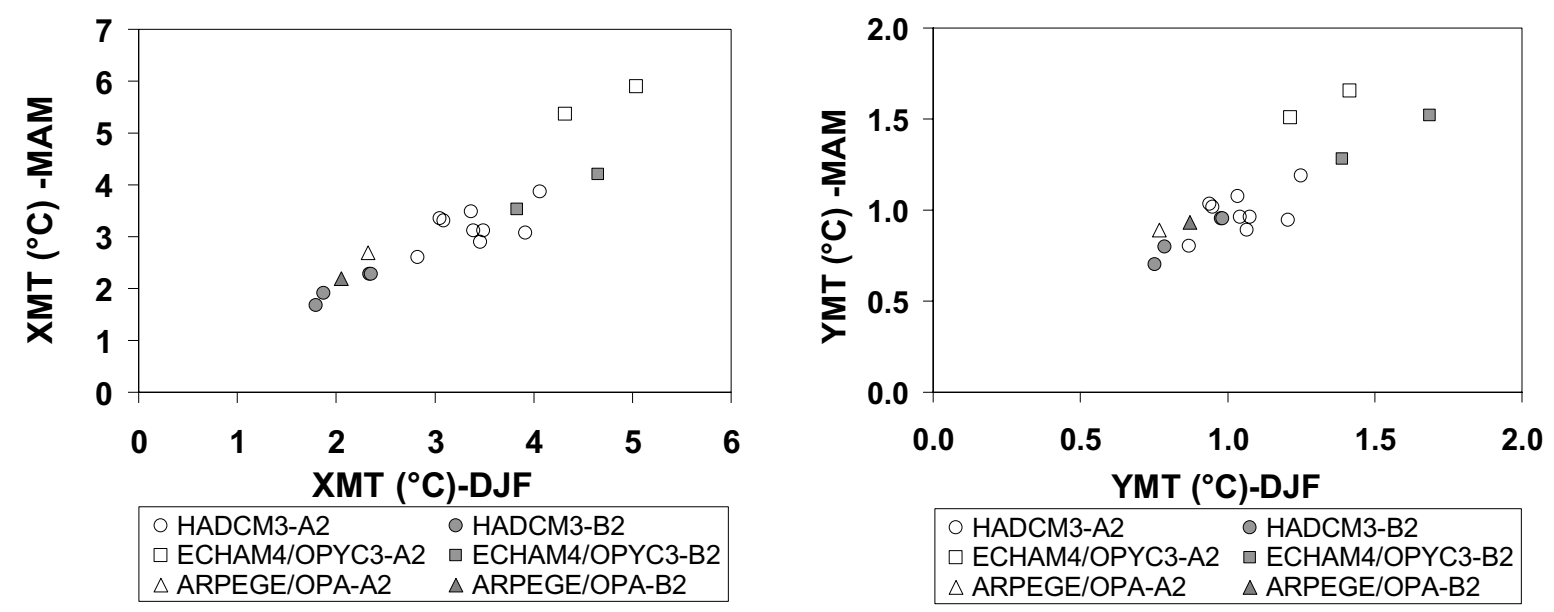

Fig. 3. Left: correlation between regional temperature changes during winter and spring ( $\mathrm{XMT}_{\mathrm{DJF}, \mathrm{I}}$ and $\mathrm{XMT}_{\mathrm{MAM}, \mathrm{i}}$ ); right: correlation between corresponding scaling ratios $\left(\mathrm{YMT}_{\mathrm{s}, \mathrm{r}}=\mathrm{XMT}_{\mathrm{s}, \mathrm{r}} / \Delta \mathrm{T}_{\mathrm{P}}\right.$ ); data from 19 RCMs obtained from Christensen et al., (2002), if ensemble runs are available, only one RCM is used.

them for $\mathrm{A} 2$ and 7 for B2 (Table 2). For some RCMs, ensemble runs exist (Table 2). This leads to a total of 26 response patterns used in the present work.

Within the PRUDENCE project, the seasonal means of surface air temperature $(M T)$ and precipitation $(M P)$ have been produced for each experiment for the whole of Europe on a $0.5^{\circ}$ latitude by $0.5^{\circ}$ longitude grid. In the absence of standard deviations of daily temperatures $(S D T)$ and coefficients of variation of daily precipitations (CVP), PRUDENCE has produced grids of 90-days' temperature and precipitation variances for each season, obtained for each run (control and future) from the 30 -values series (one series for each season) of 90-days mean temperatures (90days precipitation amounts). These 90-days' statistics have been estimated directly from the RCM output series. For the 30 years from 2070-2099, a significant temperature trend has been simulated that could potentially influence the estimation of variances. For the seasonal variances of precipitation, this influence is probably small but, for the temperature variances, it could be significant. Consequently, the PRUDENCE data cannot be used directly for the perturbation of observed daily series but has to be preprocessed according to the method briefly explained in Appendix 2. For the lake system studied, the regional changes in mean and variability are extracted for the 35 grid boxes encompassing the entire catchment and are averaged over this area. The inter-RCM variability of regional climate changes and of related scaling ratios is given for all seasons in Fig. 4.

Note that the input data required for the hydrological models are daily series of precipitation, temperature, evaporation from free water surfaces and potential evapotranspiration. The future evaporation and PET series are interpolated as a function of the future temperature based on the observed relationship for the control climate, assuming that this relationship remains constant in the future (strong linear regression relationships have been found between monthly PET and monthly temperature over the period 1961-1990). The pattern scaling approach could be extended to these variables but they were not available.

\section{Simulation framework}

Based on the pattern scaling technique, the uncertainty due to global-mean warming and to the regional response patterns can be quantified through Monte Carlo simulations. The global-mean warming is drawn randomly in a PDF for the global temperature change between 1990 and the period 2070-2099 derived from the results of Wigley and Raper (2001) for the years 2070, 2080, 2090 and 2100 (provided by Tom Wigley). The random draw of a response pattern among the 26 patterns available from PRUDENCE is based on a hierarchical resampling approach.

The following considerations motivated the use of this resampling approach: the RCM experiments and corresponding response patterns belong to different classes and sub-classes. For some RCMs, ensemble runs are available. The RCM experiments driven by the same AOGCM can be expected to give similar results and can, thus, be clustered according to the driving AOGCM. The response patterns obtained for the $\mathrm{A} 2$ and the $\mathrm{B} 2$ emission scenarios can differ significantly due to potentially significant non-linearities in the climate change response to the story lines (see Schneider and Thompson, 1981; 

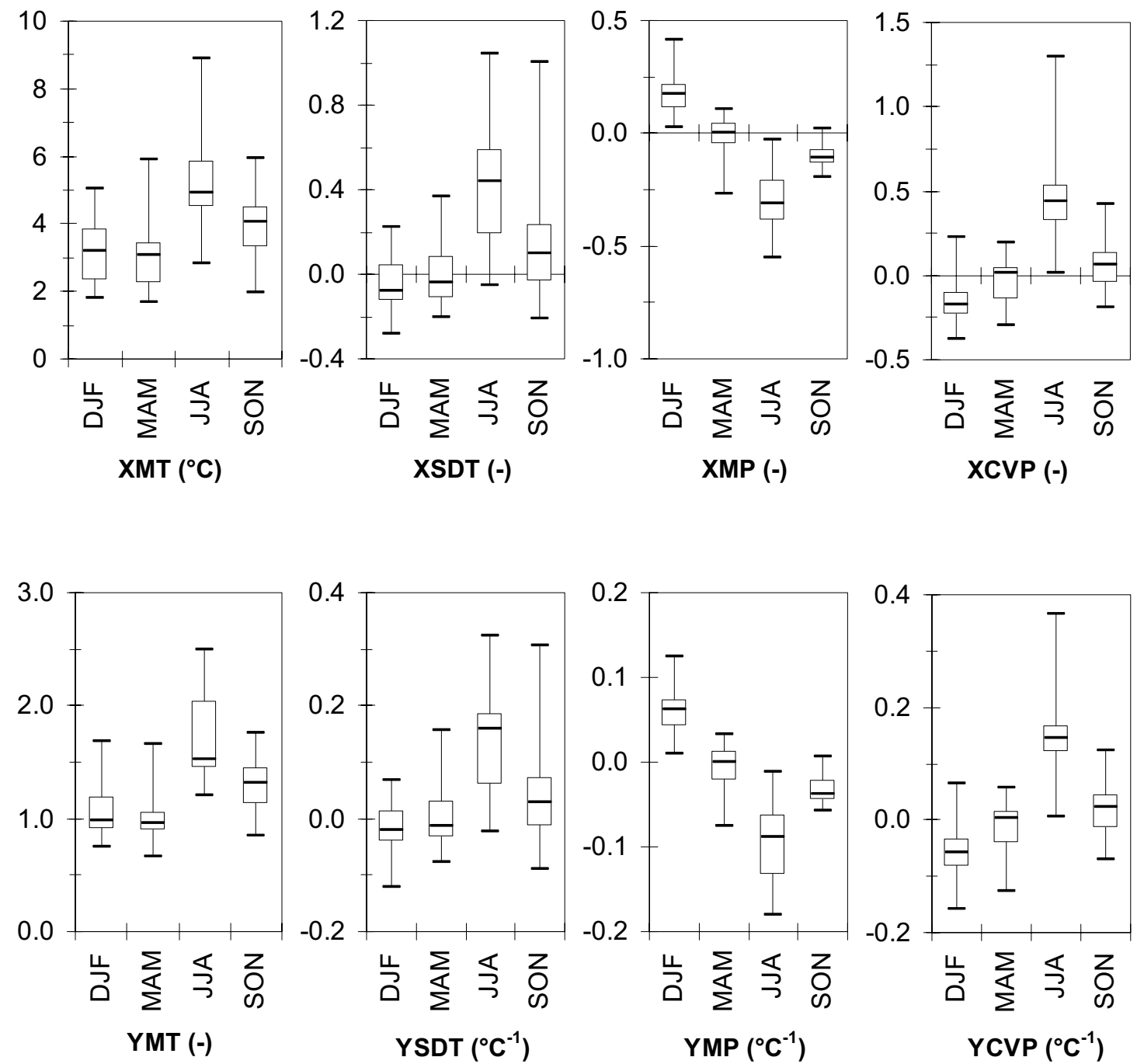

Fig. 4. Boxplots of regional climate changes X (top) and related seasonal scaling ratios $\mathrm{Y}$ (bottom) for the 4 key variables $\mathrm{MT}$, SDT, MP and CVP. X and Y variables values are based on PRUDENCE outputs (from 90-days temperature and precipitation series); SDT and CVP values have been corrected before perturbation (see Appendix 2). Each boxplot displays the variation of the seasonal regional climate change and of the scaling ratio of the 26 RCM experiments of the PRUDENCE project (all available ensemble runs are included). The whiskers represent the smallest and the largest values, the box the quartiles and the horizontal bar the median.

Mitchell, 2003). Consequently, the AOGCM clusters can be clustered in turn according to the underlying emission scenario (see Table 2).

The A2 and B2 SRES-scenarios are assumed to have the same probability of occurrence. Similarly, all AOGCM and RCM models are assumed to perform equally well. Although this may not be the case, it is the simplest assumption to make. The number of experiments within each cluster is, however, variable (for example 14 experiments in the cluster HadCM3/HadAM3H-A2, 2 experiments in the cluster ECHAM4/OPYC3-A2; 17 and 9 experiments for A2 and $\mathrm{B} 2$ respectively). The assignment of a uniform occurrence probability to all experiments would therefore lead to an over-representation of some experiments. The ARPEGE/
OPA/ARPEGE-A2 experiment for example would be drawn 9 times more frequently than the HADCM3/HADAM3H/ CHRM-A2 experiment. A detailed analysis of the data (not discussed here but some results are given in Hingray et al., 2007) has shown that the inter-RCM variability and the interAOGCM variability have the same order of magnitude. Consequently, the same occurrence probability is assigned to all AOGCM/RCM experiments of an emission cluster.

Based on the above considerations, the following hierarchical resampling approach is adopted for this work:

i. Randomly select an emission scenario (A2 or B2).

ii. Randomly draw an AOGCM/RCM experiment within the selected emission scenario cluster. 
iii. If ensemble runs are available, randomly draw the response pattern of one of the runs.

At each resampling step, all possible choices have the same occurrence probability. The uncertainties due to the differences between the emission scenarios and the uncertainties due to the system unpredictability under a given emission scenario are thus sampled uniformly.

The random generation of a response pattern could also be based on a stochastic approach using parametric models. Hingray et al. (2007) assumed that the scaling variables from the PRUDENCE dataset follow a normal distribution. The parameters of this distribution can be estimated from the observed scaling ratios using an appropriate unbalanced ANalysis Of VAriance framework (ANOVA). Following such an approach, the probability distributions of the regional temperature and precipitation change can be obtained through Monte Carlo simulation by combining a probability distribution of the global-mean temperature increase with the probability distributions of the appropriate scaling variables. Such PDFs are presented for five case study regions in Hingray et al. (2007). As mentioned before, some scaling variables are significantly correlated. A Principal Components Analysis (PCA) can be performed on the scaling variable dataset to produce a dataset of uncorrelated variables $\left[Z_{k, r}\right]_{k: 1,16 ; r: 1.26}$ where $r$ refers to the RCM experiment and $k$ to the $k^{\text {th }}$ component (all components are used for the description of the response pattern $\boldsymbol{Y}_{\boldsymbol{r}}$ ). Each transformed $Z_{k, r}$ variable can be modelled by a normal distribution, the parameters of which are estimated with an ANOVA framework. Finally, a transformed $\left[Z_{k, r}\right]_{k: 1.16 ; r: 1.26}$ response pattern can be generated stochastically and transformed back to produce a response pattern $\left[Y M T_{s}\right.$, $\left.Y S D T, Y M P_{s}, Y C V P_{s}\right]_{s: 1.4}$ with correlated variables. Schaefli et al. (2007) have applied this parametric approach to the generation of climate change scenarios. In the present study, the non-parametric resampling approach is used.

\section{Results}

The meteorological time series observed for the control period (1961-1990) are used to produce the reference discharge series for the Aare, Broye and Jura catchments and the corresponding time series of water levels, from which the reference statistics of the welfare indices are estimated. The same simulation procedure is applied for each climate change scenario. Note that the lake regulation rules for the control and the future period are those corresponding to the $1982-2000$ period.

A main objective of the present study is to quantify, separately, the climate change prediction uncertainty due to the global-mean warming and that induced by the regional response pattern. Consequently, climate change scenarios are generated according to the following three different simulation experiments:

- E1: random global-mean warming and random regional response pattern

- E2: random global-mean warming under median regional response pattern

- E3: random regional response pattern under median global-mean warming

For the experiments E1 and E2, 12000 Monte Carlo simulations were carried out whereas for E3, only 26 simulations, corresponding to the 26 available RCM runs were completed. The E3 scenarios are generated based on the median global-mean warming value as predicted by the PDF adopted for the global-mean warming between 1990 and 2070-2099 $\left(\Delta T_{E 3}=2.6^{\circ} \mathrm{C}\right)$. For E2, the median response pattern is derived from the 26 PRUDENCE response patterns. Each scaling variable $Y_{v, s}$ of this median response pattern corresponds to the median of the 26 corresponding scaling variables $Y_{v, s, r}$.

\section{RESULTS FOR E1 EXPERIMENT (OVERALL}

\section{UNCERTAINTY)}

\section{Changes in regional meteorological variables}

The simulations results show a higher regional mean warming than the global-mean warming: The median scaling ratio for the mean annual temperature is around $+1.3^{\circ} \mathrm{C}$ per ${ }^{\circ} \mathrm{C}$ of global-mean warming. The $5^{\text {th }}, 50^{\text {th }}$ and $95^{\text {th }}$ percentiles of the regional warming are $+1.8{ }^{\circ} \mathrm{C},+3.3{ }^{\circ} \mathrm{C}$ and $+6.1^{\circ} \mathrm{C}$. The regional warming in summer is higher, with a larger uncertainty range than the regional warming for the other seasons. The $99^{\text {th }}$ percentile of the summer warming is as large as $+11^{\circ} \mathrm{C}$ (only around $+7^{\circ} \mathrm{C}$ for the other seasons). The $5^{\text {th }}$ and $95^{\text {th }}$ percentiles of the relative change of annual precipitation are $-16 \%$ and $+2 \%$. This suggests that the direction of the change is uncertain. Precipitation is, however, expected to increase in winter (up to $32 \%$ increase for the $99^{\text {th }}$ percentile) and to decrease in summer and autumn (decrease of $-24 \%$ in autumn and $-68 \%$ in summer for the $1^{\text {st }}$ percentile). No trend is predicted for spring precipitation: an increase is as likely as a decrease $(-22 \%$ for the $5^{\text {th }}$ percentile, $+11 \%$ for the $95^{\text {th }}$ percentile (Hingray et al., 2007)).

The predicted range of daily temperature and precipitation variability change is large, especially for the summer season (Fig. 2). For most seasons and for both variables, a decrease in variability is as likely as an increase. A significant trend 
is observed only for summer (the precipitation and temperature variability is expected to increase) and for winter (the precipitation variability is expected to decrease). These results are illustrated (Fig. 4) based on the regional changes predicted by the PRUDENCE RCMs (note that the predicted changes obtained by combining the global-mean warming and regional response uncertainties are larger than those of Fig. 4).

Changes in mean monthly water levels and potential impacts An increase in the mean monthly lake level is as likely as a decrease (except for May and June, for which slight decreases of 5 and $10 \mathrm{~cm}$, respectively, are expected, Fig. 5 , top left). For all months, the difference between the $5^{\text {th }}$ and $95^{\text {th }}$ percentiles of these projections is small. The largest range of water level variation (around $20 \mathrm{~cm}$ ) is observed in summer (May to August). In late autumn, in winter and early spring, this range is less than $5 \mathrm{~cm}$. This suggests that the current regulation rules are also appropriate for the future climate scenarios.

For the majority of the future scenarios, the annual water level fluctuations simulated are less than those for the control period (Fig. 5 top right, Fig. 6 right). For the control period, the annual water level fluctuations are always higher than $50 \mathrm{~cm}$; for $40 \%$ of the years, it is higher than $75 \mathrm{~cm}$. For the median future conditions, these annual fluctuations (50 and $75 \mathrm{~cm}$ respectively) are exceeded for only $80 \%$ and $20 \%$ respectively of the years. The same results are obtained for the maximum water level fluctuation over a three- or fiveyear period. For the reed population, the future conditions are, thus, expected to be worse than the control conditions.

The simulated annual maximum water levels are also expected to be smaller for the future scenarios than for the control period (Fig. 6 left). The simulated future conditions are, thus, expected to be less critical for riparian urban areas than the control conditions. The same conclusion can be drawn about high water levels potentially damaging seeds and plants in maturation (Fig. 7, right).

The overall reproduction success of pikes is expected to decrease (Fig. 7 left). For most future scenarios, the number of zero global success scores increases significantly $(+100 \%$ for median future conditions compared to the control period). These results are due mainly to a shift in the arrival date of the spring flood induced by earlier snowmelt following increases in temperature. For several years, this shift leads to a zero S2 score.

\section{RESULTS FOR THE E2 AND E3 EXPERIMENTS}

The previous results do not change significantly if one source of prediction uncertainty - either the global-mean warming or the regional response - is considered separately. The trends identified (criterion increase or decrease) remain unchanged for all variables studied but the variability range decreases significantly and for some, this reduction may corresponds to a decrease of $100 \%$ or more. This is clearly illustrated by the results for the mean monthly water levels (Fig. 5 left, top, centre and bottom) or for several percentiles of the maximum annual water level fluctuation (Fig. 5 right, top, centre and bottom). The contribution of the global-mean warming uncertainty to the variability of the system behaviour for future conditions is of the same order of magnitude as the contribution of the uncertainty in the regional response. Combining both sources of uncertainty does not just sum the respective variability ranges as the total variability is much higher. These results are in line with those obtained by Horton et al. (2006), Hingray et al. (2007) and by Schaefli et al. (2007). For five case study regions, Hingray et al. (2007) show that the variance of the simulated regional climate changes due to RCM inter-model differences contributes substantially to the total variance. Schaefli et al. (2007) analyse impacts of climate change on the performance of an alpine hydropower production system by successively integrating the uncertainties due to the management model, the hydrological model, the future glacier surface estimation, the regional response to globalmean warming and the global-mean warming itself. They also conclude that a significant part of the total prediction uncertainty can be attributed to the uncertainty in the regional response to climate change. In climate change studies currently available, the emission scenario and the driving climate model are generally assumed to determine a predominant part of the regional climate change uncertainty (e.g. Jenkins and Lowe, 2003). The results presented here suggest that this assumption may not always be valid and that more attention should be paid to the interRCM variability.

\section{Conclusion}

The methodology in this paper enables a probabilistic assessment of potential climate changes and their related impacts on a real-world water resources system. The climate changes predicted are highly uncertain but the results obtained show that they are likely to have a significant impact on the lake system under study.

The regional climate change scenarios are obtained through scaling the regional response patterns resulting from RCM runs by global-mean warming projections from a simple climate model. This scenario generator allows globalmean warming uncertainty to be combined with the uncertainty inherent in the regional climate response. For 

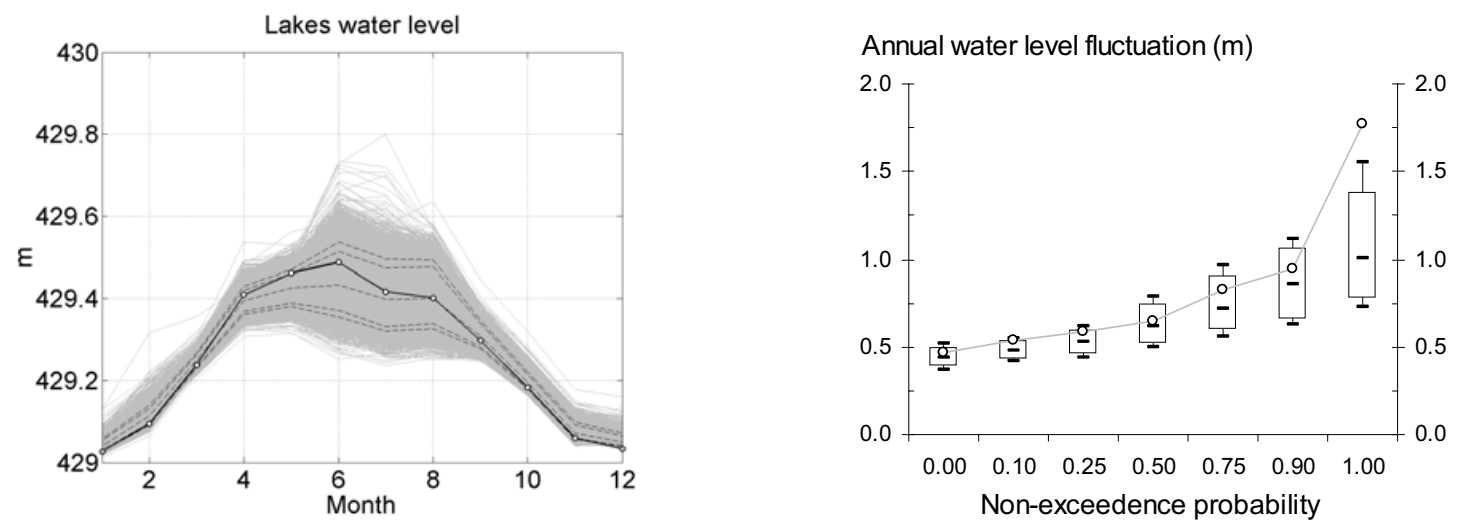

E1) Uncertain global-mean warming and uncertain scaling relationship (12000 simulations)
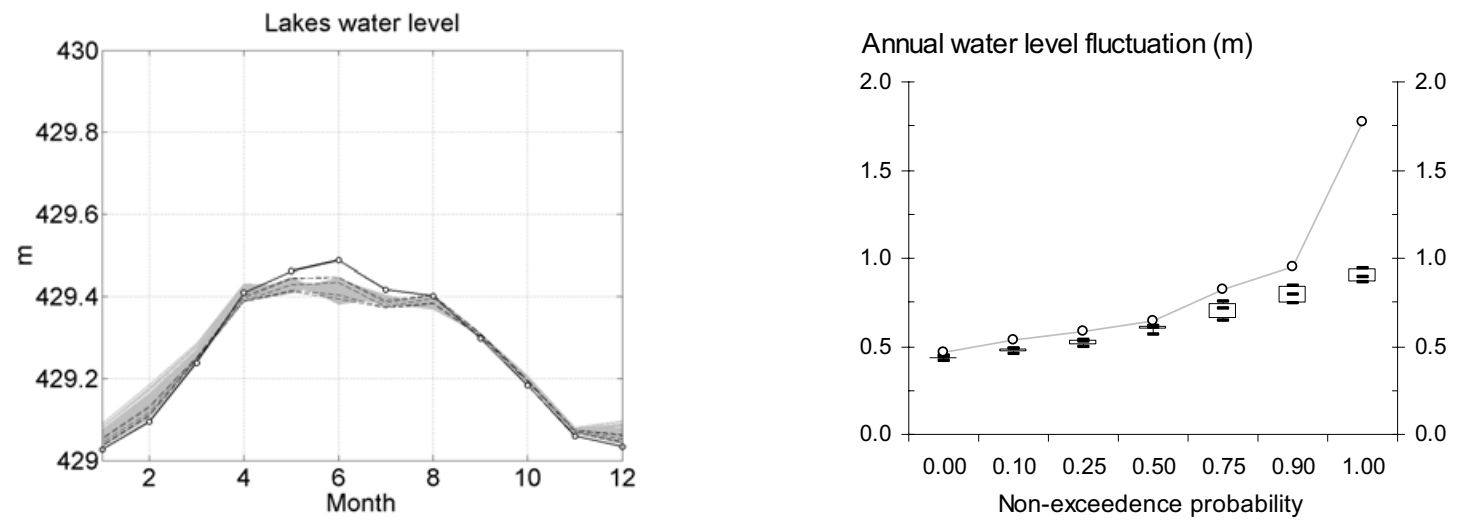

E2) Uncertain global-mean warming and median scaling relationship (12000 simulations)
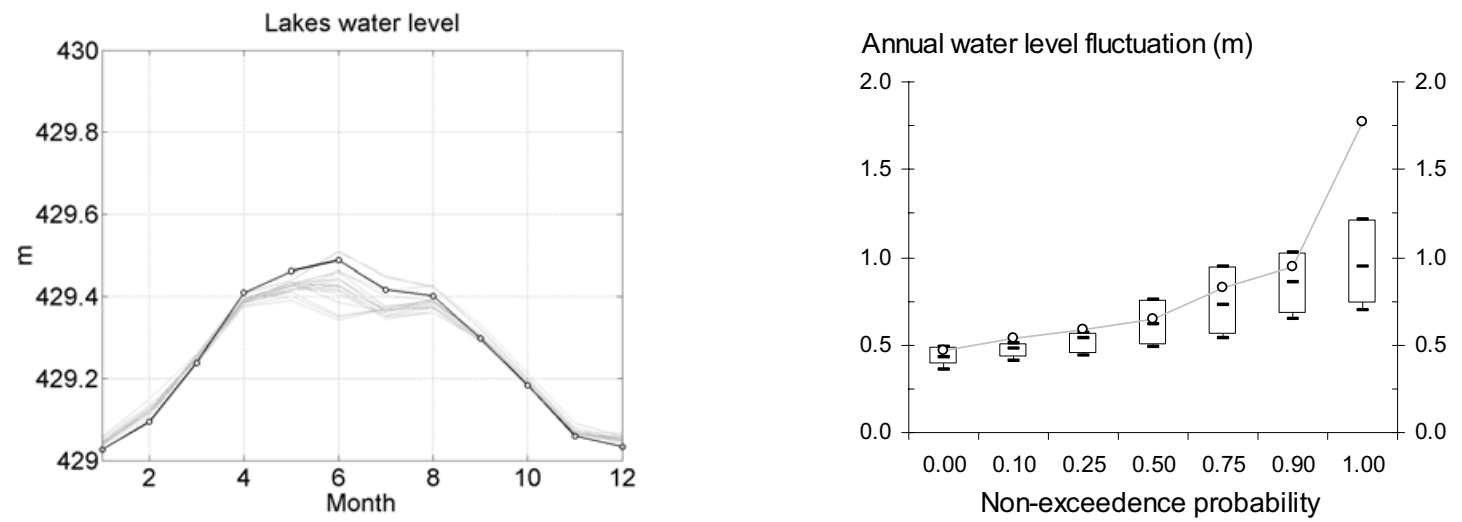

E3) Median global-mean warming $\left(2.6{ }^{\circ} \mathrm{C}\right)$ and uncertain scaling relationships (26 simulations)

Fig. 5. Variability of water level regimes obtained for the three experiments E1, E2, E3. Left: mean monthly lake levels; (circular marker = control situation; for E1 and E2, the dotted lines indicate the $5^{\text {th }}, 10^{\text {th }}, 50^{\text {th }}, 90^{\text {th }}$ and $95^{\text {th }}$ percentiles obtained from the 12000 simulations for the future climate change scenarios; for E3, each grey line corresponds to the response to one of the 26 RCM response patterns). Right: boxplots of maximum annual water level fluctuation for different non-exceedence probabilities. For explanation of the boxplots, see Fig. 4. 


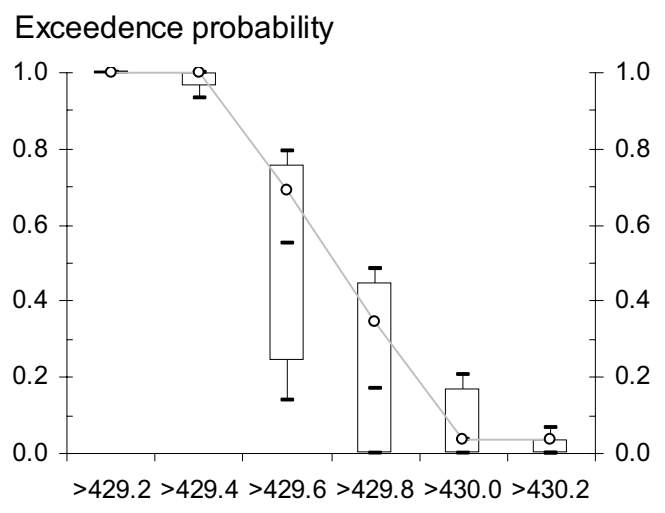

Maximum annual water level $(\mathrm{m})$

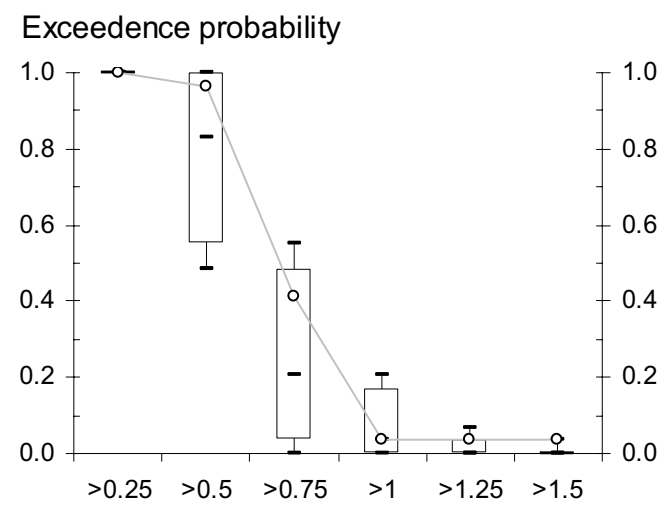

Annual water level fluctuation (1y)

Fig. 6. Variability of the water level regimes obtained with experiment E1 (including global-mean warming uncertainty and regional response uncertainty). Left: exceedence probability of the maximum annual water level; right: exceedence probability of the annual water level

fluctuation. The exceedence probability is obtained for each future scenario from the number of years within the 30 -years simulation period for which a given threshold is passed. The boxplots refer to the variability of this variable within the set of 12000 future scenarios. For explanation of the boxplots, see Fig. 4.
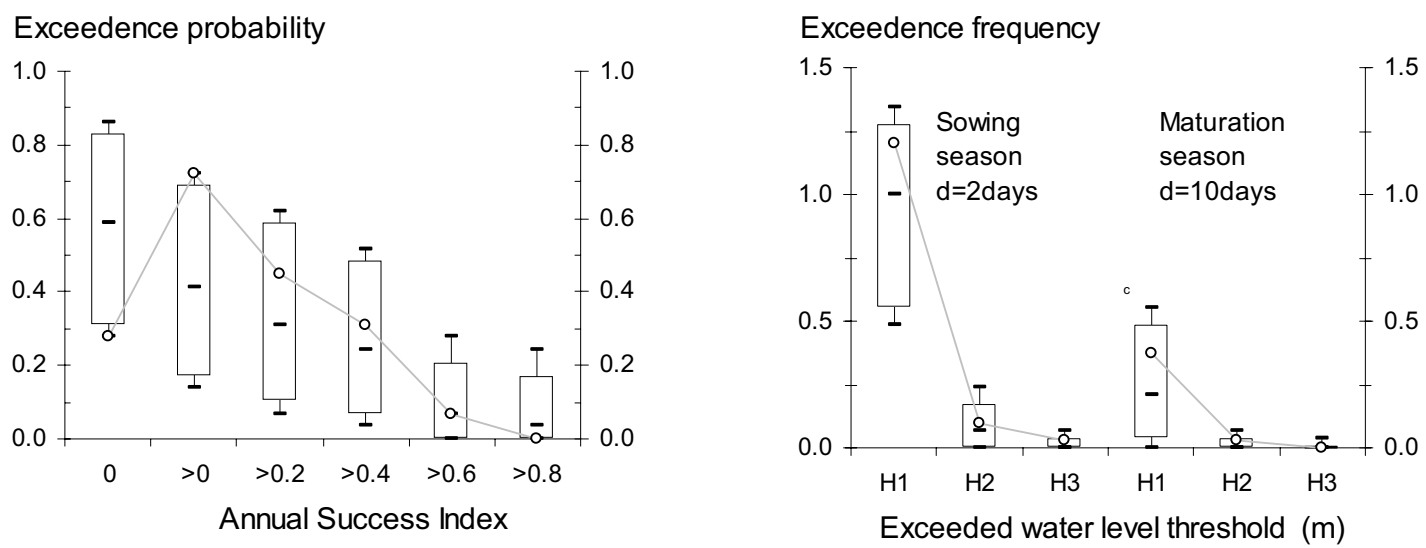

Fig. 7. Variability of performance indices obtained with experiment E1 (including global-mean warming uncertainty and regional response uncertainty); left: exceedence probability of the annual pike reproduction success; right: annual exceedence frequency of spring and summer flooding events related to agriculture (H1 $=429.5 \mathrm{~m}$ a.s.l., H2=429.75 $\mathrm{m}$ a.s.l. and H3=430 $\mathrm{m}$ a.s.l. $)$. For explanation of the boxplots, see Fig. 4.

all fields studied, the uncertainty due to inter-RCM variability contributes much of the total uncertainty in predicting the impact of climatic change and, indeed, may be as large as the uncertainty induced by the global-mean warming. This shows that the uncertainty of the regional response to global-mean warming should not be neglected in studies of the impact of climatic change.

The results presented are conditional on the models, data and modelling assumptions used. The methodology for the generation of the local scale time series has the advantage of simplicity but has also some drawbacks as potential changes in weather frequency or persistence are not quantified (see Mearns et al., 1996, for an illustration of possible related impacts). This is especially critical when extreme events are analysed (floods, droughts). Even on a seasonal time step, the risk of extreme events in a future climate is not negligible (Palmer and Räisänen, 2002; Schär et al., 2003). Potential long-term droughts such as that in 2003 experienced all over Europe or, possibly, $n$-days of extreme rainfall events, cannot be simulated with a simple scaling approach whatever the number of generated scenarios.

Using the RCM output time series directly as an input to local system models could help in overcoming these limits. As RCM experiments are very time-consuming, they cannot be used to simulate the number of scenarios required for a probabilistic impact assessment. Especially in mountain regions, the precipitation time series derived by these models are still too unreliable to be used directly as input to a hydrological model. Orographic precipitation is one of the most difficult variables to simulate in climate models (Giorgi and Mearns, 1991). Consequently, current research pays 
increasing attention to downscaling models that connect the local meteorological variables to variables describing meteorological situations on a synoptic scale (for a review of such methods, see Xu, 1999; Zorita and von Storch, 1999; Prudhomme et al., 2002). Such downscaling techniques could also be applied to simulate, for the control period, the natural climate variability, the characterisation of which would formally be required for a complete impact assessment (e.g., Hingray et al., 2006).

It would also be interesting to quantify the uncertainties due to the hydrological modelling to show whether they increase the uncertainty ranges induced by the climate scenarios. In the present work, the rainfall-excess to runoff relationships are assumed to remain constant in the future. This assumption may be critical for the regression-based models applied to the Aare and Jura catchments. Schaefli et al. (2007) showed for another case study in the Swiss Alps that the uncertainty in the estimation of the hydrological model parameters is small compared to those introduced by the climate change scenarios. The choice of the model structure could, however, have a larger influence (Schaefli et al., 2004; Schaefli, 2005). It would also be interesting to compare the results of this study with results from a more detailed hydrological model including an explicit model of the large water reservoirs in the Aare catchment.

The impact assessment methodology is also worthy of further investigation. The evaluation of the impacts of climate change on highly different and sometimes competing water-dependent interests related to human activities or ecosystem conservation remains a very difficult task. The present study outlines a possible solution but does not pretend to approach this problem in its entire complexity. The welfare indices defined give at least a partial view of potential climate change impacts on the different fields of interests and enable a statistical analysis. Such a simple statistical analysis quantifying the intensity, frequency and duration of impacts is, however, insufficient for the analysis of natural systems. A meaningful analysis of the impacts of climate change on ecosystems should ideally be based on ecological simulation tools to model the long-term evolution of the populations studied.

\section{Acknowledgements}

This work is part of the 2001-2004 SWURVE (Sustainable Water: Uncertainty, Risk and Vulnerability in Europe) project, funded under the EU Environment and Sustainable Development programme, framework V, grant number EVK1-2000-00075. The Swiss part of this project was funded by the Federal Office for Education and Science, contract number 00.0117 . The authors thank the Swiss
Federal Office of Hydrology and Geology for providing the discharge data and the national weather service MeteoSwiss for providing the meteorological time series.

The authors would like to express their gratitude to the members of the PRUDENCE (Prediction of Regional scenarios and Uncertainties for Defining EuropeaN Climate change risks and Effects) project for having made available the seasonal RCM grids on which the present work is based. The PRUDENCE project is funded under the EU Environment and Sustainable Development programme, framework V, grant number EVK2-CT-2001-00132. Acknowledgement is also made to Tom Wigley for providing the global-mean warming PDFs, as well as to Bernard Büttiker (fishery inspector of Canton de Vaud), Catherine Strehler Perrin and Michel Antoniazza (study and management group of the Grande Cariçaie) and Jean-Pierre Clément (Swiss Agency for the Environment, Forests and Landscape) for their help during the development of the impact indices.

\section{References}

Aebischer, A., 1994. La réussite de la reproduction des oiseaux nicheurs de la rive sud du lac de Neuchâtel. Mandat du Laboratoire de recherches hydrauliques, Eidgenössische Technische Hochschule Zürich, Switzerland.

Arnell, N.W. and Hulme, M., 2000. Implications of climate changes for large dams and their management. Thematic Review II. 2 prepared as an input to the World Commission on Dams, Cape Town (http://www.dams.org).

Arribas, A., Gallardo, C., Gaertner M.A., and Castro, M., 2003. Sensitivity of the Iberian Peninsula climate to a land degradation. Clim. Dynam., 20, 477-489.

Buttler, A., Cornali, P. and Bueche, M., 1995. Etude des effets de la régulation des lacs subjurassiens sur la végétation et le milieu. Rapport final, Laboratoire d'écologie végétale et de phytosociologie de l'Université de Neuchâtel, Switzerland.

Christensen, J.H., Carter, T.R. and Giorgi, F., 2002. PRUDENCE employs new methods to assess European Climate Change. EOS Trans., AGU, 83, 147.

Christensen, J.H., Räisänen, J., Iversen, T., Bjørge, D., Christensen, O.B. and Rummukainen, M., 2001. A synthesis of regional climate change simulations - A Scandinavian perspective. Geophys. Res. Lett., 28, 1003-1006.

Clerc, C., 1999. Suivi scientifique des roselières lacustres. Résultats 1993-1998. Champ-Pittet, Switzerland.

Denk, M., 2002. Modelling of a regulated lake system and sustainability evaluation of management rules. A case study on the three Jura lakes, Switzerland. Diploma thesis, Ecole Polytechnique Fédérale de Lausanne, Switzerland.

Doms, G. and Schättler, U., 1999. The Nonhydrostatic LimitedArea Model LM (Lokal-Modell) of DWD, Part I: Scientific Documentation, Deutscher Wetterdienst, Meteorologische Analyse und Modellierung, Offenbach, Germany.

Ekström, M., Hingray, B., Mezghani, A. and Jones, P.D., 2007. Regional climate model data used within the SWURVE project 2: addressing uncertainty in regional climate model data for five European case study areas. Hydrol. Earth Syst. Sci., 11, 1085-1096. 
Fowler, H.J., Kilsby, C.G. and O'Connell, P.E., 2003. Modeling the impacts of climatic change and variability on the reliability, resilience, and vulnerability of a water resource system. Water Resour. Res., 39, 1222, doi:10.1029/2002WR001778.

Frei, C., Christensen, J.H., Deque, M., Jacob, D., Jones, R.G. and Vidale, P.L., 2003. Daily precipitation statistics in regional climate models: Evaluation and intercomparison for the European Alps. J. Geophys. Res.- Atmos., 108 (D3), 4124, doi: 10.1029/2002JD002287.

Gibelin, A.L. and Déqué, M., 2003. Anthropogenic climate change over the Mediterranean region simulated by a global variable resolution model. Clim. Dynam., 20,327-339.

Giorgi, F. and Mearns, L.O., 1991. Approaches to the simulation of regional climate change: a review. Rev. Geophys., 29, 191216

Giorgi, F., Marinucci, M.R. and Bates, G.T., 1993a. Development of a second generation regional climate model (REGCM2). Part I: Boundary layer and radiative transfer processes. Mon. Weather Rev., 121, 2794-2813.

Giorgi, F., Marinucci, M. R., Bates, G. T. and DeCanio, G., 1993b. Development of a second generation regional climate model (REGCM2). Part II: convective processes and assimilation of lateral boundary conditions. Mon. Weather Rev., 121, 28142832.

Gordon, C., Cooper, C., Senior, C.A., Banks, H., Gregory, J.M., Johns, T.C., Mitchell, J.F.B. and Wood, R.A., 2000. The simulation of SST, sea ice extents and ocean heat transports in a version of the Hadley Centre coupled model without flux adjustments. Clim. Dynam., 16, 147-168.

Hashimoto, T., Stedinger, J.R. and Loucks, D.P., 1982. Reliability, Resiliency, and Vulnerability Criteria for Water Resource System Performance Evaluation. Water Resour. Res., 18, 1420 .

Hingray, B., Mezghani, A., Schaefli, B., Niggli, M., Faivre, G., Guex, F., Hamdi, Y., Musy, A. 2006. Estimation des débits de crue du Rhône à Porte du Scex et autres points amont caractéristiques. Projet CONSECRU 2. Rapport final. HYDRAM. Ecole Polytechnique Fédérale de Lausanne, Lausanne, Switzerland, 190p.

Hingray, B., Mezghani, A. and Buishand, A., 2007. Development of probability distributions for regional climate change from uncertain global-mean warming and an uncertain scaling relationship. Hydrol. Earth Syst. Sci., 11, 1097-1114.

Horton, P., Schaefli, B., Mezghani, A., Hingray, B.and Musy. A., 2006. Assessment of climate change impacts on Alpine discharge regimes with climate model uncertainty. Hydrol. Process., 20, 2091-2109.

Hulme, M., Jenkins, G.J., Lu, X., Turnpenny, J.R., Mitchell, T.D., Jones, R.G., Lowe, J., Murphy, J.M., Hassell, D., Boorman, P., McDonald, R. and Hill, S., 2002. Climate Change Scenarios for the United Kingdom: The UKCIP02 Scientific Report, Tyndall Centre for Climate Change Research, School of Environmental Sciences, University of East Anglia, Norwich, UK.

Huntingford, C. and Cox, P.M., 2000. An analogue model to derive additional climate change scenarios from existing GCM simulations. Clim. Dynam., 16, 575-586.

Jacob, D., 2001. A note to the simulation of the annual and interannual variability of the water budget over the Baltic Sea drainage basin. Meteorol. Atmos. Phys., 77, 61-73.

Jakeman, A.J. and Hornberger, G.M., 1993. How much complexity is warranted in a rainfall-runoff model. Water Resour. Res., 29, 2637-2649.

Jasper, K., Calanca, P., Gyalistras, D. and Fuhrer, J., 2004. Differential impacts of climate change on the hydrology of two alpine river basins. Climate Res., 26, 113-129.
Jaton, J.-F., 1989. IIe Correction des eaux du Jura: effets du règlement 1980 - 82 de régulation des lacs en matière hydroagricole - rapport final, Laboratory of Hydrology and Land Improvement, Ecole Polytechnique Fédérale de Lausanne, Switzerland.

Jenkins, G. and Lowe, J., 2003. Handling uncertainties in the UKCIP02 scenarios of climate change., Hadley Centre, Technical note 44, Exeter, UK.

Jones, R.N., 2000. Analysing the risk of climate change using an irrigation demand model, Climate Res., 14, 89-100.

Katz, R.W. and Brown, B.G., 1992. Extreme events in a changing climate: variability is more important than averages. Climatic Change, 21, 289-302.

Kim, J., 2005. A projection of the effects of the climate change induced by increased $\mathrm{CO} 2$ on extreme hydrologic events in the western US. Climatic Change, 68, 153-168.

Lane, M.E., Kirshen, P.H. and Vogel, R.M., 1999. Indicators of impacts of global climate change on U. S. water resources. $J$. Water Resour. Plan. Man-ASCE, 125, 194-204.

Lettenmaier, D.P., Wood, A.W., Palmer, R.N., Wood, E.F. and Stakhiv, E.Z., 1999. Water resources implications of global warming: An U.S. regional perspective. Climatic Change, 43, 537-579.

Loukas, A., Vasiliades, L. and Dalezios, N.R., 2002. Potential climate change impacts on flood producing mechanisms in southern British Columbia, Canada using the CGCMA1 simulation results. J. Hydrol., 259, 163-188.

Maisch, M., Wipf, A., Denneler, B., Battaglia, J. and Benz, C., 2000. Die Gletscher der Schweizer Alpen: Gletscherhochstand 1850, aktuelle Vergletscherung, Gletscherschwund-Szenarien. Schlussbericht NFP 31. Hochschul-Verlag an der ETH, Zürich, $373 \mathrm{pp}$.

Martinec, J., Rang,o A. and Major, E., 1983. The snowmelt-runoff model (SRM) user's guide. Nasa Reference Publ. 1100. Washington, D.C., USA.

Mearns, L.O., Rosenzweig, C. and Goldberg, R., 1996. The effect of changes in daily and interannual climatic variability on cereswheat: A sensitivity study. Climatic Change, 32, 257-292.

Mermoud, A., 1995. Méthodes et techniques d'irrigation. Notes de cours, Ecole Polytechnique Fédérale de Lausanne, Switzerland.

Mitchell, J.F.B., Johns, T.C., Eagles, M., Ingram, W.J. and Davis, R.A., 1999. Towards the construction of climate change scenarios. Climatic Change, 41, 547-581.

Mitchell, T.D., 2003. Pattern scaling - An examination of the accuracy of the technique for describing future climates. Climatic Change, 60, 217-242.

Monteith, J.L. and Unsworth, M., 1990. Principles of environmental Physics, Second edition, Editions Arnold, London, UK. $291 \mathrm{pp}$.

Nakicenovic, N. and Swart, R. (Eds.), 2000. Special Report on Emissions Scenarios (Intergovernmental Panel on Climate Change). Cambridge University Press, Cambridge, UK. 570pp. New, M. and Hulme, M., 2000. Representing Uncertainty in Climate Change Scenarios: a Monte Carlo approach. Integr. Assess. 1, 203-213.

Palmer, T.N. and Räisänen, J., 2002. Quantifying the risk of extreme seasonal precipitation events in a changing climate. Nature, 415, 512-514.

Pope, V.D., Gallani, M.L., Rowntree, P.R. and Stratton, R.A., 2000. The impact of new physical parametrizations in the Hadley Centre climate model - HadAM3. Clim. Dynam., 16, 123-146.

Prudhomme, C., Jakob, D., and Svensson, C., 2003. Uncertainty and climate change impact on the flood regime of small UK catchments. J. Hydrol., 277, 1-23. 
Prudhomme, C., Reynard, N. and Crooks, S., 2002. Downscaling of global climate models for flood frequency analysis: where are we now? Hydrol. Process., 16, 1137-1150.

Räisänen, J., 2001. CO2-induced climate change in CMIP2 experiments: Quantification of agreement and role of internal variability. J. Climate, 14, 2088-2104.

Räisänen, J., 2002. $\mathrm{CO}_{2}$-induced changes in interannual temperature and precipitation variability in 19 CMIP2 experiments. J. Climate, 15, 2395-2411.

Räisänen, J., Hansson, U., Ullerstig, A., Döscher, R., Graham, L. P., Jones, C., Meier, H.E.M., Samuelsson, P. and Willén, U., 2004. European climate in the late 21 st century: regional simulations with two driving global models and two forcing scenarios. Clim. Dynam., 22, 13-31.

Roeckner, E., Bengtsson, L., Feichter, J., Lelieveld, J. and Rodhe, H., 1999. Transient climate change simulations with a coupled atmosphere-ocean GCM including the tropospheric sulfur cycle. J. Climate., 12, 3004-3032.

Royer, J.F., Cariolle, D., Chauvin, F., Déqué, M., Douville, H., Planton, S., Rascol, A., Ricard, J.L., Salas y Melia, D., Sevault, F., Simon, P., Somot, S., Tyteca, S., Terray, L. and Valcke, S., 2002. Simulation of climate changes during the 21 st century including stratospheric ozone. CR Geosci., 334, 147-154.

Santer, B.D., Wigley, T.M.L., Schlesinger, M.E. and Mitchell, J.F.B., 1990. Developing climate scenarios for equilibrium GCM results. MPI report 47, Hamburg, Germany.

Schaefli, B., 2005. Quantification of modelling uncertainties in climate change impact studies on water resources: Application to a glacier-fed hydropower production system in the Swiss Alps. Doctoral Thesis, Ecole Polytechnique Fédérale de Lausanne, $209 \mathrm{pp}$, http://library.epfl.ch/theses, thesis no 3225.

Schaefli, B., Hingray, B. and Musy, A., 2004. Improved calibration of hydrological models: use of a multi-objective evolutionary algorithm for parameter and model structure uncertainty estimation. In: Hydrology: Science and Practice for the 21st Century, B.W. Webb et al. (Eds.), British Hydrological Society, London, UK. 362-371.

Schaefli, B., Hingray, B. and Musy, A., 2007. Climate change and hydropower production in the Swiss Alps: quantification of potential impacts and related modelling uncertainties. Hydrol. Earth Syst. Sci., 11, 1191-1205.

Schär, C., Vidale, P.L., Lüthi, D., Frei, C., Häberli, C., Liniger, M.A. and Appenzeller, C., 2004. The role of increasing temperature variability in European summer heatwaves. Nature, doi: 10.1038 /nature 02300 .

Schneider, S.H. and Thompson, S.L., 1981. Atmospheric $\mathrm{CO}_{2}$ and climate-importance of the transient response. J. Geophys. Res. Oceans Atmos. 86, 3135-3147.

Zorita, E. and von Storch, H., 1999. The analog method as a simple statistical downscaling technique: comparison with more complicated methods. J. Climate, 12, 2474-2489.

\section{Appendix 1 : Perturbation of daily rainfall series (according to Shabolova et al., 2003)}

The Weibull distribution is assumed to give a reasonable fit to the distribution of the daily rainfall amounts. For a random variable $U$ (daily rainfall amount) with the distribution function $F(u)$ where $u$ is a realisation of $U$, the Weibull distribution is defined as
Schreider, S.Y., Whetton, P.H., Jakeman, A.J. and Pittock, A.B., 1997. Runoff modelling for snow affected catchments in the Australian alpine region, Eastern Victoria. J. Hydrol. 200, 123.

Shabalova, M.V., Van Deursen, W.P.A. and Buishand, T.A., 2003. Assessing future discharge of the river Rhine using regional climate model integrations and a hydrological model. Climate Res., 23, 223-246.

Spreafico, M., Weingartner, R. and Leibundgut, C., 1992. Atlas hydrologique de la Suisse. Service Hydrologique et Géologique National, Bern, Switzerland.

Steel, M., 1999. Historic rainfall, climatic variability and flood risk estimation for Scotland. PhD thesis, University of Dundee, UK.

SwissTopo, 1997. Digital National Maps of Switzerland - PM25, Wabern, Switzerland.

VAW, 1996. Régularisation optimale de la IIe correction des eaux du Jura (IIe CEJ). 3941 F, Versuchsanstalt für Wasserbau, Hydrologie und Glaziologie der Eidgenössischen Technischen Hochschule Zürich, Switzerland.

Vidale, P.L., Lüthi, D., Frei, C., Seneviratne, S. and Schär, C., 2003. Predictability and uncertainty in a Regional Climate Model. J. Geophys. Res.-Atmos., 108 (D18), 4586, doi: 10.1029/ 2002JD002810, 2003.

Vogel, R.M., Lane, M., Ravindiran, R.S. and Kirshen, P.H., 1999. Storage reservoir behavior in the United States. J. Water Resour. Plan. Man.-ASCE, 125, 245-254.

Whetton, P., Haylock, M. and Galloway, R., 1996. Climate change and snow-cover duration in the Australian Alps. Climatic Change, 32, 447-479.

Wigley, T.M.L. and Raper, S.C.B., 2001. Interpretation of High Projections for Global-Mean Warming. Science, 293 (5529), 451-454.

Wigley, T.M.L., Raper, S.C.B., Smith, S. and Hulme, M., 2000. The Magicc/ScenGen Climate Scenario Generator: version 2.4: Technical Manual, CRU, UEA, Norwich, U.K.

$\mathrm{Xu}$, C.Y., 1999. From GCMs to river flow: a review of downscaling methods and hydrologic modelling approaches. Prog. Phys. Geogr., 23, 229-249.

Young, P., 1984. Recursive Estimation and Time-Series Analysis. Springer, Berlin, Germany.

Young, P., 1993. Time variable and state dependent modelling of non-stationary and non-linear time series. In: Developments in Time Series Analysis, T. Subba Rao (Ed.), Chapman and Hall, London, UK. 374-413.

Young, P. and Beven, K., 1994. Data-based mechanistic modelling and the rainfall-flow non-linearity. Environmetrics, 5, 335-363.

Zaugg, B., Pedroli, J.C. and Zaugg, C., 1994. Incidences des fluctuations du niveau du lac de Neuchâtel sur la faune piscicole. Rapport du bureau Aquarius, Neuchâtel, Switzerland.

$$
F(u)=\operatorname{Pr}(U \leq u)=1-\exp \left[-(u / \alpha)^{c}\right]
$$

where $\operatorname{Pr}(U \leq u)$ is the probability that $U \leq u$ and $\alpha$ and $c$ are the scale and the shape parameter. For such a distribution, the $p t h$ quantile has the expression:

$$
u_{p}=\alpha[-\ln (1-p)]^{1 / c}
$$

For the observed data, both parameters $\alpha_{o b s}$ and $c_{o b s}$ are estimated by the method of moments such that the distribution preserves the observed mean $\left(M P_{o b s}\right)$ and 
coefficient of variation $\left(C V P_{o b s}\right)$. The theoretical values for the mean and the variance are:

$$
\begin{aligned}
E(u) & =\alpha \cdot \Gamma\left(\frac{1}{C}+1\right) \\
\operatorname{Var}(u) & =\alpha^{2}\left[\Gamma\left(\frac{2}{C}+1\right)-\left[\Gamma\left(\frac{1}{C}+1\right)\right]^{2}\right]
\end{aligned}
$$

For the future time series scenario, the mean $\left(M P_{\text {scen }}\right)$ and the variation coefficient $\left(C V P_{\text {scen }}\right)$ of the daily rainfall amounts are estimated from the observed mean $\left(M P_{o b s}\right)$ and the observed variation coefficient $\left(C V P_{o b s}\right)$ and their relative changes given by the regional climate change statistics (XMP and $X C V P$ ). The Weibull parameters for the future scenario $\alpha_{\text {scen }}$ and $c_{\text {scen }}$ are estimated by the method of moments (Eqns A1.3 and A1.4). It is assumed that if the daily rainfall amount $u_{o b s}(t)$ observed on day $t$ corresponds to the $p$ th quantile in the observed series, the scenario value $u_{\text {scen }}(t)$ for the same date corresponds to the same quantile in the scenario series. From these assumptions and Eqn. A1.2 it follows:

$$
u_{\text {scen }}{ }^{(t)}=\alpha_{\text {scen }} \cdot\left(\frac{u_{o b s}(t)}{\alpha_{o b s}}\right)^{\frac{c_{o b s}}{c_{s c e n}}}
$$

Note that the Weibull distribution parameters are estimated independently for each season (for both the observed and the future scenario).

\section{Appendix 2: Estimation of daily variances from PRUDENCE data}

\section{DETRENDING FUTURE TEMPERATURE SERIES}

The variances used in PRUDENCE to describe the variability of the temperatures are estimated from the 30 values of 90-days temperature $T_{s, k}$, where $k$ refers to the $k^{\text {th }}$ year of the 30 -years period and where $T_{s, k}$ is the mean temperature value for the $s^{\text {th }}$ season of this year. The future temperature series can show considerable trends, especially the runs obtained for the A2 scenario, and this trend could have a non-negligible effect on the estimated variance and the related standard deviation. The time series $T_{s, k}$ should, therefore, be detrended. The effect of the temperature trend on the variance can be estimated without knowing the individual seasonal values. The expected temperature increase during the $21^{\text {st }}$ century is assumed linear in time.
The difference in the mean seasonal temperature between the future and the control run will, therefore, give a reasonable estimate of the total trend $\Delta_{s}$ for the years 2070 2099 relative to season $s$ (Eqn. A2.1):

$$
\Delta_{s}=X M T_{s}^{*} 30 / 110
$$

where $X M T_{s}=M T_{\text {future, }}-M T_{\text {control.s }}$ is the change in mean seasonal temperature over this 110 -years period and where $\Delta_{s}$ is the trend for the years $2070-2099$ for season $s$ (in ${ }^{\circ} \mathrm{C}$ per 30 years). Note that for the period 1961-1990, the change in temperature is probably not large enough to have a marked influence on the standard deviations of the seasonal temperatures. Let $T_{s, 1}, T_{s, 2}, \ldots, T_{s, n}$ be the mean 90-days temperature values as simulated by the RCM for the period 2070-2099 $(n=30)$ for season $s$ and $\sigma_{s}^{2}$ the variance estimated based on this series:

$$
\sigma_{s}^{2}=\frac{1}{n-1} \sum_{i=1}^{n}\left(T_{s, i}-M T_{s, \text { future }}\right)^{2} .
$$

If the trend is linear, it can be easily shown that the mean of $\sigma_{s}^{2}$ is given by

$$
\mathrm{E}\left(\sigma_{s}^{2}\right)=S D T_{90, s}^{2}+\frac{1}{12} \Delta_{s}^{2}(1+1 / n) \approx S D T_{90, s}^{2}+\frac{1}{12} \Delta_{s}^{2}
$$

where $S D T_{90, s}{ }^{2}$ is the true variance of the detrended series. If an estimate of $\sigma_{s}$ and of $\Delta_{s}$ is known, an almost unbiased estimate of $S D T_{90, s}$ can be obtained.

\section{PERTURBATION OF DAILY SERIES BASED ON 90-} DAYS STATISTICS

The PRUDENCE data yields 90-day statistics that cannot be used directly to perturb the observed daily temperature and precipitation series. For the daily variation coefficients $C V P$, a linear regional relationship has been identified between this variable and the 90-days' coefficients of variation based on 15 observed rainfall time series located in the region under study. Such a linear relationship is identified for each of the four seasons $s$.

For temperatures, the change in the daily standard deviations $X S D T$ is set equal to the change in the 90-days standard deviations $X S D T_{90}$. It can be easily shown that, in this case, the perturbation of the observed daily series based on Eqn. 2 gives a future daily series that preserves the relative change in the 90-days standard deviations. 